\title{
Regioselective Photocycloaddition of Saccharin Anion to \#-systems: Continuous-Flow Synthesis of Benzosultams
}

Francisco Nicolás Figüeroa, Adrián Alberto Heredia, Alicia B. Peñeñory, Diego Sampedro, Juan E. Argüello, and Gabriela Oksdath-Mansilla

J. Org. Chem., Just Accepted Manuscript • DOI: 10.1021/acs.joc.8b02984 • Publication Date (Web): 04 Mar 2019

Downloaded from http://pubs.acs.org on March 6, 2019

\section{Just Accepted}

"Just Accepted" manuscripts have been peer-reviewed and accepted for publication. They are posted online prior to technical editing, formatting for publication and author proofing. The American Chemical Society provides "Just Accepted" as a service to the research community to expedite the dissemination of scientific material as soon as possible after acceptance. "Just Accepted" manuscripts appear in full in PDF format accompanied by an HTML abstract. "Just Accepted" manuscripts have been fully peer reviewed, but should not be considered the official version of record. They are citable by the Digital Object Identifier (DOI®). "Just Accepted" is an optional service offered to authors. Therefore, the "Just Accepted" Web site may not include all articles that will be published in the journal. After a manuscript is technically edited and formatted, it will be removed from the "Just Accepted" Web site and published as an ASAP article. Note that technical editing may introduce minor changes to the manuscript text and/or graphics which could affect content, and all legal disclaimers and ethical guidelines that apply to the journal pertain. ACS cannot be held responsible for errors or consequences arising from the use of information contained in these "Just Accepted" manuscripts. 
Keywords: photocycloaddition, sultams, flow chemistry, TDDFT,

\title{
CASSCF
}

\section{Regioselective Photocycloaddition of}

\section{Saccharin Anion to $\pi$-systems: Continuous-}

\section{Flow Synthesis of Benzosultams}

\author{
Francisco N. Figueroa,${ }^{[a], \dagger}$ Adrián A. Heredia,${ }^{[b], \dagger}$ Alicia B. Peñéñory, ${ }^{[b]}$ Diego \\ Sampedro, ${ }^{*[c]}$ Juan E. Argüello ${ }^{[b]}$ and Gabriela Oksdath-Mansilla ${ }^{[b]}$
}

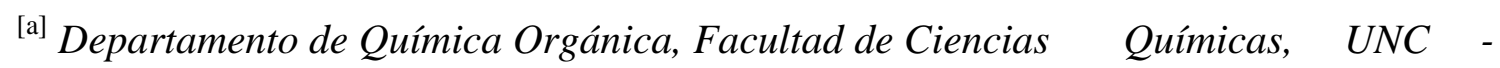
IPQA-CONICET, Ciudad Universitaria, X5000HUA Córdoba, Argentina.

[b] INFIQC-CONICET-UNC, Dpto. de Química Orgánica, Facultad de Ciencias Químicas, Universidad Nacional de Córdoba, Ciudad Universitaria, X5000HUA Córdoba, Argentina, *goksdath@fcq.unc.edu.ar, jea@fcq.unc.edu.ar.

${ }^{[c]}$ Departamento de Química, Universidad de La Rioja, Madre de Dios, 53, Logroño, 26006, Spain, diego.sampedro@unirioja.es

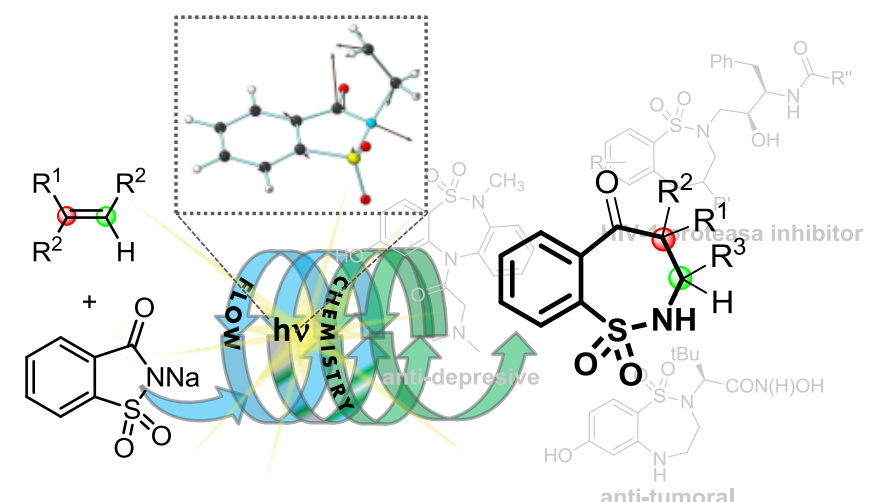

Graphical Abstract 


\begin{abstract}
Saccharin is a versatile scaffold to build up different heterocycles with relevance in asymmetric catalysis, agricultural chemistry, medicinal chemistry, etc. Here, we report a photochemical strategy to obtain seven-member ring benzosultams in one step, using saccharin anion as staring material. The reaction can be improved in a photo-flow reactor and its scope was evaluated. Furthermore, computational study at the CASPT2//CASSCF level of theory was also performed in order to rationalize the involved mechanism.
\end{abstract}

\title{
Introduction
}

Benzosultam is a common functionality present in many different biologically active compounds and, thus, a relevant target for drug discovery. These heterocyclic sulfonamides are more rigid and may assume fewer conformations compared to open chain sulfonamides which in turn make these compounds relevant pharmaceuticals with a broad spectrum of biological activities. Sulfonamide substituent is present in more than $25 \%$ of sulfur-containing pharmaceuticals within the 12 representative diseases. Sulfonamides also have an extensive biological profile, known to exhibit antibacterial, anti-carbonic anhydrase, diuretic, hypoglycemic, antithyroid, anti-inflammatory, anticonvulsant, antihypertensive, and anticancer properties (Figure 1). ${ }^{1}$ A number of benzosultams have been recently reported to exhibit broad inhibitory properties against a variety of enzymes including: cyclooxygenases involved in rheumatoid arthritis, lipoxygenase, HIV integrase, Calpain I implicated in neurodegenerative processes like Alzheimer's and Parkinson's diseases, and Matrix metalloproteinases. In particular, saccharins, which include the sulfonamide moiety, have been shown to feature diverse 
biological activities. In addition, ring-expanded saccharin derivatives such as oxicams are used as anti-inflammatory drugs. ${ }^{2}$

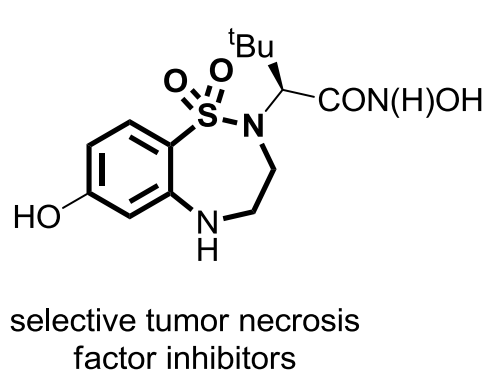

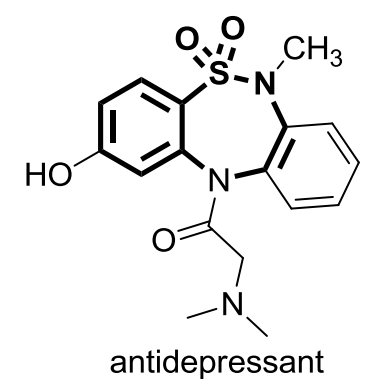

HIV-1 proteasa inhibitors

Figure 1. Examples of biologically active benzosultams derivatives.

Due to the biological importance of benzosultams, the development of different synthetic methods to prepare these compounds at large scale is of great interest for organic and medicinal chemists. ${ }^{3}$ In this context, synthetic organic photochemistry arrives as a powerful tool for the preparation of natural products as well as molecules with high structural complexity, in a simple and efficient way. Saccharin is a food grade sweetener produced annually in thousands of ton scale, its price makes it an attractive standpoint for heterocycle's synthesis. In particular, there are few reports about photochemistry of saccharins directed to their synthetic applications, although it is known that saccharin derivates are involved in different photoreactions. With $\mathrm{N}$ alkylsaccharins, for example, a homolytic N-S bond cleavage with extrusion of $\mathrm{SO}_{2}$ can be observed. ${ }^{4}$ Additionally, the photoaddition of saccharin to $\alpha$-silylamine by single electron transfer (SET) pathways was observed. ${ }^{5}$ The intramolecular photoreaction of $N$-[(trimethylsilyl)alkyl]saccharins shows a competitive silyl group transfer, homolysis of the S-N bond and H-abstraction processes. ${ }^{6}$ More recently, the photocyclization reactions of $N$-(thioalkyl)-saccharins were carried out in our group to obtain different polycyclic sultams in good yields. ${ }^{7}$ These results motivated us to continue exploring the photoreactivity of saccharin oriented to synthetic applications. In this work, we focused 
on the synthesis of benzo-fused seven-membered sultams by photocycloaddition reaction.

Reported synthesis of benzo-fused seven-membered sultams, usually involve more than a single step. For example, Ganguly et al. described a protocol to obtain HIV-1 protease inhibitors using a radical cyclization reaction with tributyltin hydride (TBTH) in the presence of AIBN and refluxing toluene. ${ }^{8}$ However in this case, previous preparation of starting materials was necessary, by reaction of allylamine/2-methylallylamine with 2bromobenzenesulfonyl chloride in pyridine (Scheme 1a, step 1). In another approach, Hanson and co-workers developed a methodology to obtain benzothiazepenones through $\operatorname{Pd}(0)$-catalyzed Heck cyclization and subsequent ozonolysis reaction. ${ }^{9}$ To access to heterocycles of interest, substrate had to be previously synthesized via polar coupling of corresponding sulfonyl chloride with $L$-amino methyl ester and allylation with allyl bromide (Scheme 1b).

Based on the multiple steps involved in the synthesis of seven-membered sultams compounds as time demanding procedure, we designed a novel, straightforward and more convenient synthetic method in one-pot to obtain seven-membered sultams which involve the use of commercially available and inexpensive reagents under mild conditions (Scheme 1c). 
a)

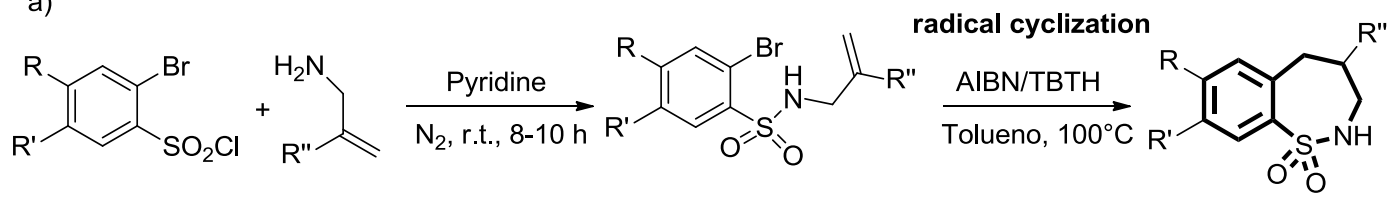

b)

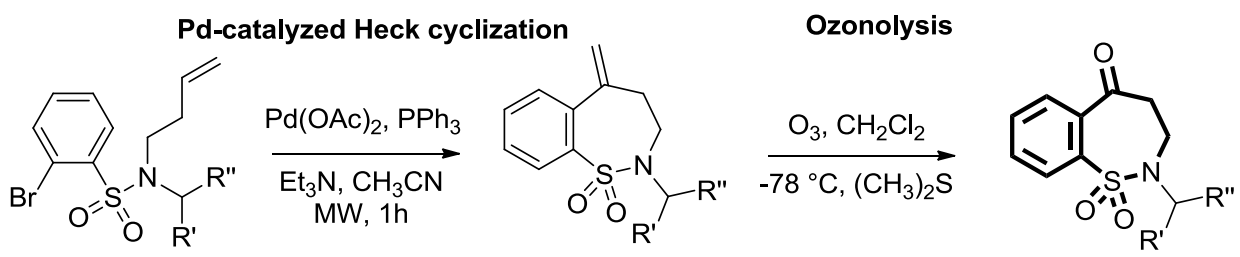

c) this work<smiles>[R]C=C([R])[Y][Y][Y5]1C(=O)c2ccccc2S1(=O)=O</smiles>

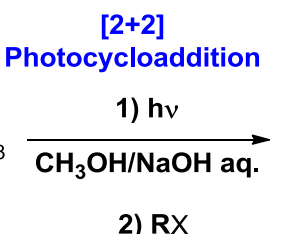

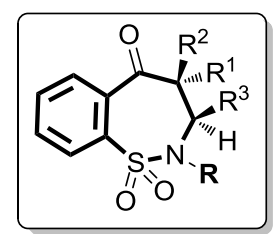

commercially available

reagents

one-pot

transition- metal- free

greener conditions

flow approach

Scheme 1. Approaches to obtain benzo-fused seven-membered sultam derivatives.

On the other hand, in recent years, considerable interest has been focused on the use of continuous-flow chemistry for photochemical transformations. Due to the narrow width of the reactor tubing (Beer-Lambert law) a more efficient light absorption is observed compared to batch reactions. Flow chemistry offers a better control over reaction conditions such as flow-rates/volumes/concentrations, which allows control over competing reactions or side-products. Additionally, an improved reaction selectivity and increased reproducibility are observed, resulting in an easy scaling-up using different reactor volumes or parallel multi-reactors (numbering-up). ${ }^{10}$ Such benefits can be related to the increased surface-to-volume ratio in microchannels. The advantages of continuous-flow process have allowed improving photochemical syntheses and nowadays interesting applications in the synthesis of heterocycles and in drug discovery processes can be found. ${ }^{11}$ Furthermore, threre is a growing interest in applying different 
scale-up strategies of continuous multistep synthesis to develop active pharmaceutical ingredients (APIs) which incluide at least one photochemical step. ${ }^{12}$

With all of these and considering that saccharin derivatives can participate in different photoreactions as reagents for the synthesis of heterocyclic compounds with novel rings; herein we report the study of the photocycloaddition reaction of saccharin anion with different $\pi$-systems. We evaluated the benzosultams photo-generation in a flow system and computational studies were carried out in order to explore the mechanism and explain the observed regioselectivity.

\section{Results and Discussion}

It is know that phthalimide anion is able to react with alkyl and aryl alkenes by photostimulation to form [2]benzazepine-1,5-diones. ${ }^{13}$ Based on the photoreactivity of phthalimide anion with different alkenes, we performed an exploratory study of the photocycloaddition of saccharin to $\alpha$-methyl-styrene to yield the benzosultam 1a under basic conditions. Table 1 summarizes the reaction conditions for the photocycloaddition optimization in batch.

When a solution of saccharin anion and $\alpha$-methyl-styrene was irradiated under $\mathrm{N}_{2}$ atmosphere at $300 \mathrm{~nm}$ during $24 \mathrm{~h}$, the corresponding benzosultam $1 \mathbf{a}$ was obtained in $64 \%$ yield (Table 1, entry 1). Under these conditions, only the regioisomer with the aromatic substituent at position 4 of the benzothiazepine ring moiety was isolated from the reaction mixture by column chromatography. When less equivalents of $\mathrm{NaOH}$ were used, a similar yield of the photoproduct was obtained (Table 1, entry 2 ). With a longer irradiation time $(48 \mathrm{~h})$ or with a reduction in the amount of alkene, a decrease on the yield for cycloaddition product was observed (Table 1, entries 3 and 4, respectively). Additionally, the formation of 1a was not sensitive to the atmosphere employed, since only a slight reduction in yield for 1a was observed under air atmosphere (Table 1, 
aromatic substituent at position 4 of the benzothiazepine ring moiety are favored (see Table 1). Its regiochemistry was confirmed from the HMBC experiment, in which for benzosultam 1a the methyl group C-21 was connected to C-8 (carbonyl group) by the HMBC correlations from the cross peaks of $\mathrm{H}-1 / \mathrm{C}-7$ (or $\mathrm{C} \alpha$ of the alkene) and $\mathrm{C} 8$ (calculated structure indicated in Figure S1). It could be thought that the alkene always adds with its terminal carbon (or $\mathrm{C} \beta$ ) bonded to nitrogen.

Finally, considering the fact that photocycloaddition was evaluated in heterogeneous conditions using a $\mathrm{NaOH}$ solution as base, which is not fully soluble in $\mathrm{CH}_{3} \mathrm{CN}$, the reaction was carried out using $\mathrm{CH}_{3} \mathrm{OH}$ as solvent. Under this condition and after $24 \mathrm{~h}$ of irradiation the photoproduct 1a was produced in comparable yield (72\% isolated yield, Table 1 entry 7).

Although photoreactions proceeded in good overall yield, the reaction was slow and required an excess of alkene. Considering that alkenes with aromatic substituents absorb light at similar wavelengths than the saccharine anion, a low concentration of the olefin is preferred in order to prevent competitive photoreactions. For this reason, photocycloaddition reactions employing other aryl alkenes were more difficult. With these limitations in mind, we hypothesized that the use of continuous-flow photochemistry might have an additional advantage that could improve the reaction yields and reduce the reaction times compared to batch conditions. Furthermore, this technology has the potential to scale-up the benzosultams synthesis.

In this way, a homogenous solution of saccharin anion with only 2 equivalents of $\alpha$ methyl-styrene in $\mathrm{CH}_{3} \mathrm{OH}$ were evaluated using a two-layer of fluorinated ethylene propylene (FEP) flow photoreactor with a total volume of $3.78 \mathrm{~mL}$ and flowed through the reactor by means of a HPLC pump. After optimizing flow and concentration conditions, the photocycloaddition was found to proceed with a residence time of only 
$1.83 \mathrm{~h}\left(0.06 \mathrm{~mL} \mathrm{~min}^{-1}, 0.05 \mathrm{M}\right)$, giving rise to $0.110 \mathrm{~g}$ of isolated benzosultam $1 \mathrm{a}(71 \%$ isolated yield, extrapolated value of $\left.1.44 \mathrm{~g} \mathrm{day}^{-1}\right)$.

With the optimized flow conditions in hand, the scope of the photocycloaddtion was evaluated and a series of benzosultams (1)-j') were synthesized in good to moderate isolated yields (Scheme 2).

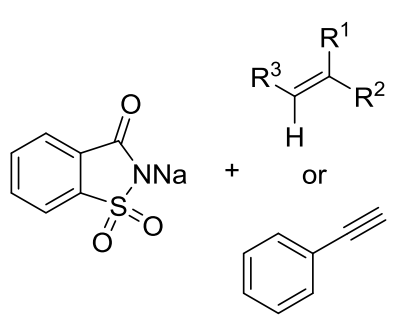

$\mathrm{MeOH} / 2$ eq. NaOH (1M) $0.05 \mathrm{M}$, rt $t_{\mathrm{r}}=1.9-9.5 \mathrm{~h}$

ID $0.45 \mathrm{~mm}$ or $0.75 \mathrm{~mm}$

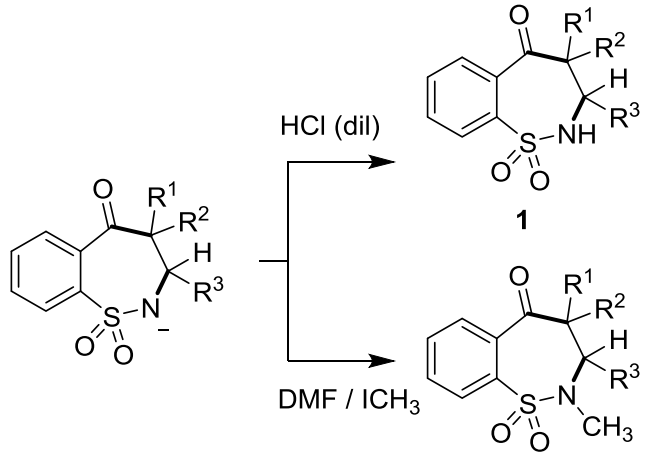

1

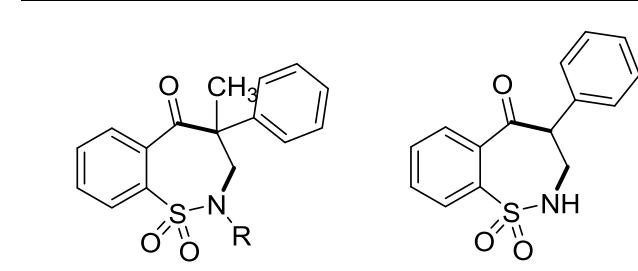

1b, $15 \%$<smiles>CC1NS(=O)(=O)c2ccccc2C(=O)[C@H]1c1ccccc1</smiles>

1c, $21 \%$<smiles>COc1ccc(C(C)N2C(=O)c3ccccc3S2(=O)=O)cc1</smiles>

1d, $13 \%$ $t_{r}=9.5 \mathrm{~h}-\mathrm{R}=\mathrm{CH}_{3}, \mathbf{a}^{\prime}, 90 \%$

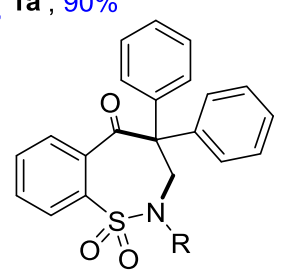

$\mathrm{R}=\mathrm{H}, \mathbf{1 e}, 30 \%$ $t_{\mathrm{r}}=9.5 \mathrm{~h}-\mathrm{R}=\mathrm{CH}_{3}, 1 \mathrm{e}^{\prime}, 84 \%$<smiles>O=C1c2ccccc2S(=O)(=O)NC2CCCCC12</smiles>

1g, $5 \%$

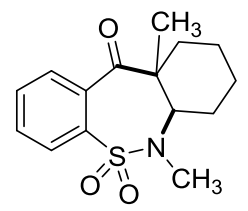

$t_{r}=9.5 \mathrm{~h}-1 \mathbf{h}^{\prime}, 55 \%$<smiles>O=C1C(c2ccccc2)=CNS(=O)(=O)c2ccccc21</smiles>

1f, $7 \%$<smiles>CN1C=C(c2ccccc2)C(=O)c2ccccc2S1(=O)=O</smiles>

1f', $35 \%$ $t_{\mathrm{r}}=9.5 \mathrm{~h}-\mathrm{R}=\mathrm{CH}_{3}, \mathbf{1 f}, 39 \%$<smiles>CN1CC(C)(COc2ccccc2)C(=O)c2ccccc2S1(=O)=O</smiles>

$t_{r}=9.5 \mathrm{~h}-1 \mathbf{j}^{\prime}, 60 \%$

Scheme 2. Scope of photocycloaddition of saccharin anion to alkenes in flow system. In blue, reactions performed in photo-flow reactor using $0.75 \mathrm{~mm}$ ID FEP. 
When photocycloaddition was carried out using styrene, the benzosultam derivate $\mathbf{1 b}$ was obtained in $15 \%$ of isolated yield. In the same way, when trans- $\beta$-methyl-styrene was evaluated, the corresponding benzosultam 1c was obtained in $21 \%$. The low yields observed for aryl styrene derivates (1) and 1c) could be rationalized by the presence of an acid hydrogen atom in $\alpha$ position to the carbonyl group, which under basic conditions it is deprotonated giving rise to competitive reactions. The structural assignment of the isolated compound $\mathbf{1 c}$ as a diastereomeric mixture was based on their ${ }^{1} \mathrm{H}$ NMR and ${ }^{13} \mathrm{C}$ NMR spectra, using NOESY experiments to establish the relative stereochemistry of the chiral centers. In this context, the interaction between $\mathrm{H}$ at position $4\left(-\mathrm{COCHPhCHCH}_{3}\right.$, doublet at $\left.\delta=4.7 \mathrm{ppm}\right)$, the methyl group ($\mathrm{COCHPhCHCH}_{3}$-doublet at $\left.\delta=1.3 \mathrm{ppm}\right)$ and the $\mathrm{N}-\mathrm{H}(\delta=5.2 \mathrm{ppm})$ signals were particularly useful for diagnostic purposes. The data were consistent with the assigned regioselectivity, moreover, the methyl group at position 3 was found to be trans to the aryl group at position 4, indicating that the relative configuration of the alkene is maintained throughout the photo-cycloaddition reaction (Scheme 2).

On the other hand, with $p$-methoxy-styrene the formation of photocycloaddition product was not observed and just a $13 \%$ of isolated yield of 1d was obtained. This addition product can be generated via SET competitive mechanism which is favored with alkenes with low ionization potentials. Similar photoaddition products were observed for the phthalimide anion in the presence of double bond of the alkene. ${ }^{14}$

The cycloaddition of saccharin anion is favored for gem-alkenes like $\alpha$-methyl-styrene and 1,1-diphenyl-styrene which allowed the formation of 1e in $30 \%$ yield. On the other hand, when phenylacetylene reacted with saccharin anion under UV-irradiation, the corresponding benzosultam 1f was formed in only $7 \%$ isolated yield (Scheme 2). When an alkyne is used, the photoproduct has an $\alpha, \beta$-unsaturated carbonyl moiety that 
increases the acidity of the $\mathrm{N}-\mathrm{H}$ group. In this particular case, the acidity of sulfonamide 1f is higher compared with saccharin $(\mathrm{pKa}=2.2) .{ }^{15}$ In all cases, the reactions were quenched by the addition of a hydrochloric acid solution to protonate the anionic photoproduct. However, when the N-H pKa of the product is low, higher amounts of acid were needed since the product is more acid and probably a considerably amount of benzosultam product was lost during the reaction work-up. To evaluate this assumption a different work-up was carried out: the photoreaction was quenched by the addition of methyl iodide $\left(\mathrm{ICH}_{3}\right)$ to perform a one-pot $\mathrm{S}_{\mathrm{N}} 2$ reaction with the anion of benzosultam 1f. Under these conditions, a $35 \%$ isolated yield of $N$-methyl benzosultam (1f') was obtained, indicating that a substantial loss of mass had occurred during the wok-up by the addition of $\mathrm{HCl}$.

Finally, cyclohexene was evaluated as an example of aliphatic alkene. In this reaction, the benzosultam $1 \mathrm{~g}$ was obtained in $5 \%$ isolated yield displaying a lower reactivity compared with arylalkenes.

In order to obtain a higher conversion, we built a new photo-flow reactor with $0.75 \mathrm{~mm}$ ID FEP and a longer path length, resulting in a total volume of $5.72 \mathrm{~mL}$. We evaluated gem- and trisubstituted alkenes that do not show competitive reactions. In all the cases the reactions were quenched by addition of IMe in order to improve mass balance of the reaction. Under the same condition of the first photo-flow reactor, we could obtain similar isolated yields for the benzosultam 1a' $\left(68 \%, 0.05 \mathrm{~mL} \mathrm{~min}^{-1}, 0.05 \mathrm{M}, t_{\mathrm{r}}=1.9 \mathrm{~h}\right)$. In this case, full conversion was observed with longer residence time of $9.5 \mathrm{~h}$, obtaining 1a' in a $90 \%$ isolated yield. On the other hand, when phenyl acetylene was evaluated a full conversion was not achieved, even with a higher residence time (19 h), obtaining $39 \%$ of isolated yield of 1f'. For the cyclohexene derivates, 1-methyl cyclohexene and 1-phenylcyclohexene, 5 equivalents were used and with the same photo-flow 
parameters, a $55 \%$ and $20 \%$ of isolated yields of $\mathbf{1 h}$ ' and $\mathbf{1 i}$ were obtained respectively. Even when the full conversion was not achieved, under these conditions better results for the cyclohexene derivates were obtained. Finally, when ((2-methylallyl)oxy)benzene was evaluated as an gem aliphatic substituted alkene, a $60 \%$ isolated yield of benzosultams product (1j') was obtained. These reactions have a considerable synthetic value taking into account that a seven-member ring is obtained in only one step and under mild reaction conditions. In addition, the preparation of these compounds can be easily up-scaled.

\section{Mechanism and Theoretical Calculations}

Reaction Mechanism. Based on the experimental results and in analogy with the proposed phthalimide anion photocycloaddition reaction study, the reaction mechanism stated in Scheme 3 can be proposed. Saccharin anion under irradiation is promoted to its single excited state, which is the reactive intermediate that gives the $[2+2]$ cycloaddition reaction with the alkene. These process can be concerted (path a, Scheme 3), stepwise involving radical ion intermediates $\mathrm{I}$ (path $\mathrm{b}$, Scheme 3), or stepwise where a nucleophilic addition of the excited saccharin to the alkene takes place, leading to an anionic intermediate II (path c, Scheme 3) which finally collapses to the azetidine heterocycle namely intermediate III. None of the intermediates I-III were observed since a very fast reaction should occur to give the more stable anion IV. Later on, this anion can be methylated or protonated to account for the observed reaction products. The regioselectivity observed in these reactions points to a stepwise or asynchronous cycloadition reaction (paths b or c, Scheme 3) where, either a radical or negative charge is stabilized by the presence of aryl substituents (phenyl groups for the styrenes studied). 


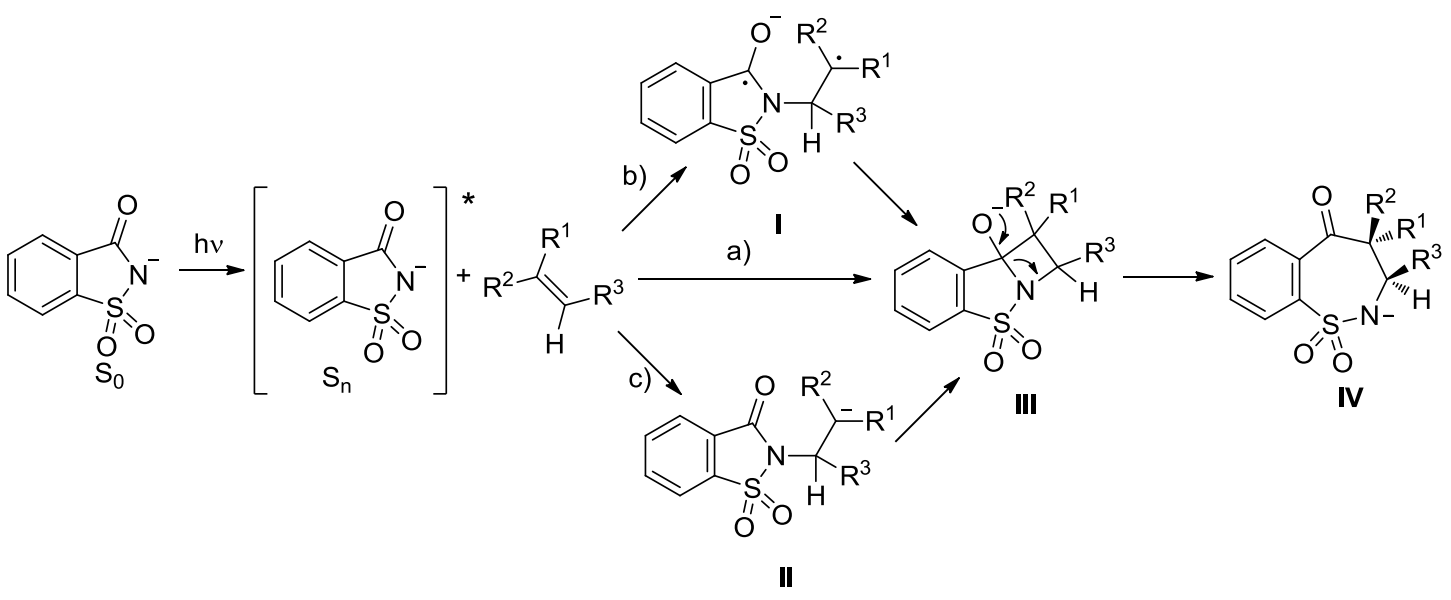

Scheme 3: Possible pathways for the benzosultam products formation.

In order to get a better insight into the reaction mechanism a photophysic study of the saccharin anion together with a computational modeling of the topology of the potential energy surface for the reaction in the excited state were performed.

\begin{abstract}
Absorption and Fluorescence Spectra. The absorption and emission spectra for saccharin anion were measured in methanol and the results are shown in Figure 2. The absorption spectrum displays a band at $267 \mathrm{~nm}$ and a broad emission band in the fluorescence spectrum with a maximum at $417 \mathrm{~nm}$ (excitation wavelength $270 \mathrm{~nm}$ ) (Figure $2 \mathrm{a}$ and $2 \mathrm{~b}$, respectively). The excitation (Figure S3) and the absorption spectra resemble each other, indicating the observed fluorescence is coming from a single excited state only. It is known that $N$-alkylsaccharins are poorly fluorescent species, ${ }^{6}$ in contrast, the saccharin anion exhibits a significant fluorescence emission at $417 \mathrm{~nm}$ in methanol $\left(\Phi_{\mathrm{f}}=0.14\right)$. In addition, time-resolved experiments were made, and the decay curve was fitted to a mono exponential function giving as result a fluorescence life time of $2.3 \mathrm{~ns}$ for the saccharin anion in basic $\mathrm{CH}_{3} \mathrm{CN}$. Also, the singlet energy of $E_{\mathrm{s}}=333$ $\mathrm{kJ} \mathrm{mol}^{-1}$ was extracted from the spectroscopic characterization; this value is lower compared to others $N$-alkyl saccharins measured. ${ }^{7}$
\end{abstract}



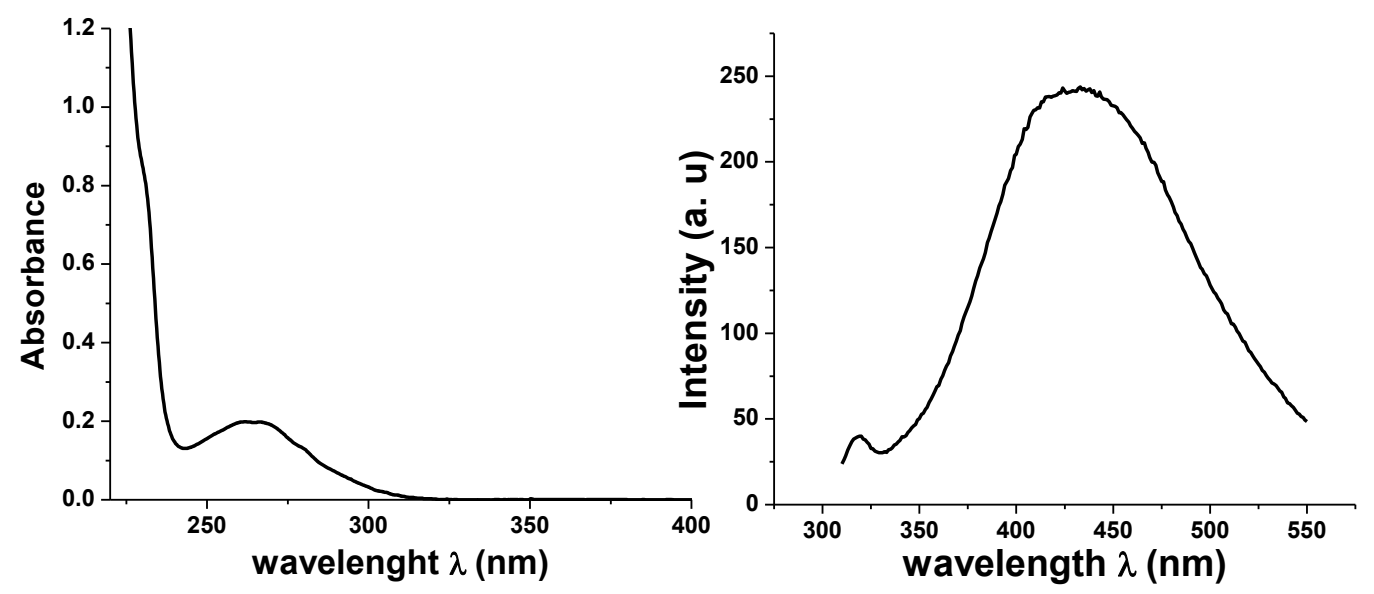

Figure 2. Absorption (a) and emission (b) spectra for saccharin anion in methanol $[$ Saccharinate $]=1 \mathrm{mM} ; \lambda_{\mathrm{exc}}=270 \mathrm{~nm}$.

Computational Study. We studied the reaction mechanism using two different model theories (see Computational Details). On one hand, we studied the photochemical part of the reaction under the CASSCF/CASPT2 level of theory. This provides a deep understanding of the processes activated by light, but it is too demanding to allow for the computation of large systems (i.e. the saccharin anion and styrene). On the other hand, we also performed a complementary TD-DFT computational study, which allows to explore the reaction mechanism including the regiochemistry study for larger systems.

First, a theoretical study of the saccharin anion was carried out to understand the underlying features involved in the photophysics and the observed photoreactivity. Therefore, as an initial step we computed the UV spectrum of saccharin anion in the gas phase at the TD-DFT and CASPT2 levels of theory (see Computational Details). At the B3LYP/6-311++G** level, two absorptions at 322 and $307 \mathrm{~nm}\left(\mathrm{~S}_{1}\right.$ and $\left.\mathrm{S}_{2}\right)$ were computed with oscillator strength values of $\mathrm{f}=0.016$ and 0.018 respectively, in qualitative agreement with the experimental band $(267 \mathrm{~nm})$. Results at the CASPT2 
level allowed gathering a deeper insight into the photophysics. The computed UV spectrum involves the $n \rightarrow \pi^{*}$ transition to $S_{1}$ with a low oscillator strength value ( $\mathrm{f}=$ 0.0003 ) while the relevant band corresponds to a $\pi \rightarrow \pi^{*}$ transition mainly located in the aromatic ring at $275 \mathrm{~nm}$ with an oscillator strength of 0.02 . Thus, the bright state for the saccharin anion is $S_{2}$ and this state will be mainly populated upon irradiation.

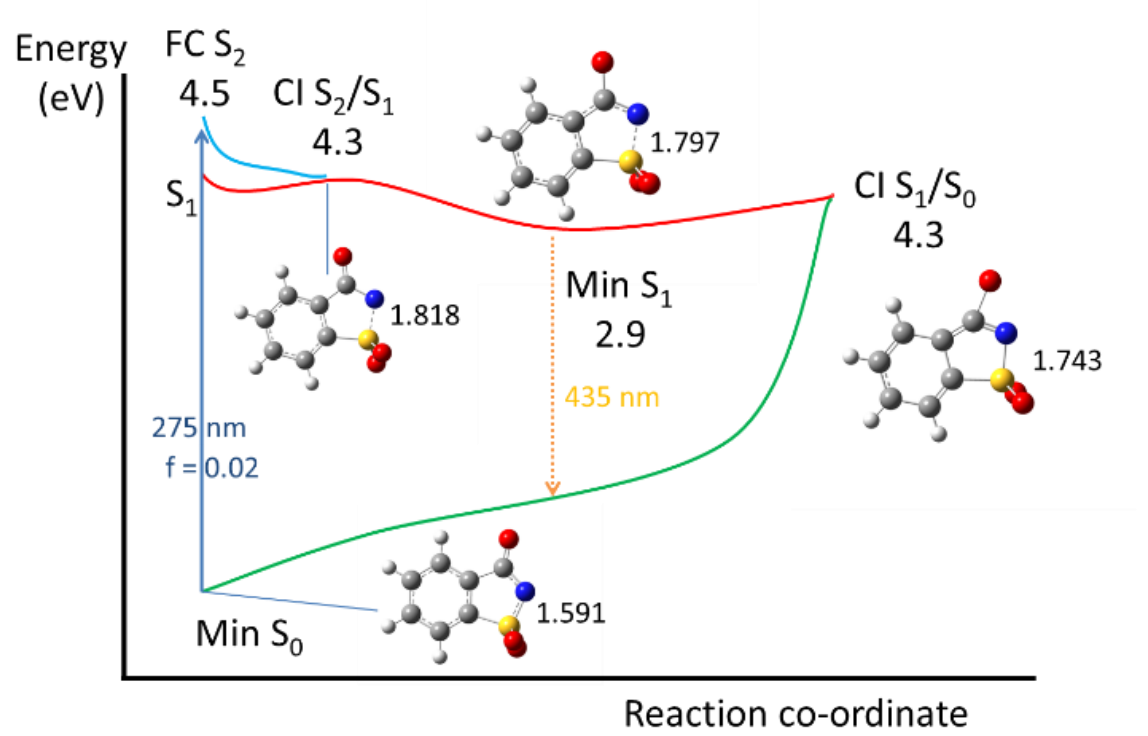

Figure 3. Critical points along the reaction coordinate for the saccharin anion computed at the CASPT2 level of theory.

Next, the excited-state deactivation of saccharin anion was explored. The critical points along the potential energy surfaces (PESs) are reported in Figure 3. After population of $\mathrm{S}_{2}$, a fast deactivation of this excited state is expected due to the proximity of the dark state $\mathrm{S}_{1}$ with an $\mathrm{n} \rightarrow \pi^{*}$ character. The elongation of the $\mathrm{S}-\mathrm{O}$ bond is the main geometrical deformation along the relaxation in $S_{2}$ until a crossing between $S_{2}$ and $S_{1}$ at a conical intersection $(\mathrm{CI})$ point is reached. After $\mathrm{S}_{1}$ population, a minimum was located with a very similar geometry to the $\mathrm{CI} \mathrm{S}_{2} / \mathrm{S}_{1}$ point. This structure is critical in order to understand the photophysics and the photochemistry of this system, as the excited molecules will be trapped in this minimum for some time. On one hand, the system 
could evolve through emission of a photon of $435 \mathrm{~nm}$ to reach the ground state, in agreement with the relatively high fluorescence experimentally measured $\left(\phi_{\mathrm{f}}=0.14\right.$, $417 \mathrm{~nm})$. Alternatively, the saccharin anion could reach a CI $S_{1} / S_{0}$ point and decay to its ground state. It should be noted that the energy of the CI is $1.4 \mathrm{eV}$ higher than the minimum in $S_{1}$. This energy barrier is relevant because the system could have enough time to react with any unsaturated species present in the reaction medium. The main geometrical distortion in this point is located in the five-member ring, especially in the $\mathrm{C}-\mathrm{N}$ bond distance as shown by the gradient difference and derivative coupling vectors (see Figure S4).

In addition, a series of theoretical calculations at the CASPT2//CASSCF level of theory were also performed in order to rationalize the mechanism involved in the photocycloaddition. Our experimental findings show that styrene derivatives offer the best results giving high yield of the photoproducts. However, due to the size of the system, these compounds are too demanding in computational resources to model at the CASPT2 level of theory. Thus, we evaluated the theoretical photocycloaddition between saccharin anion and ethylene as the model compound at out higher level of theory. It should be noted that the reaction between the saccharin anion and aliphatic alkenes, while offers moderate yields, it is also feasible (see Scheme 2), so this simplification is experimentally supported. The relevant points along the CASSCF//CASPT2 $S_{1}$ PES for the reaction of the saccharin anion with ethylene are shown in Figure 4. 


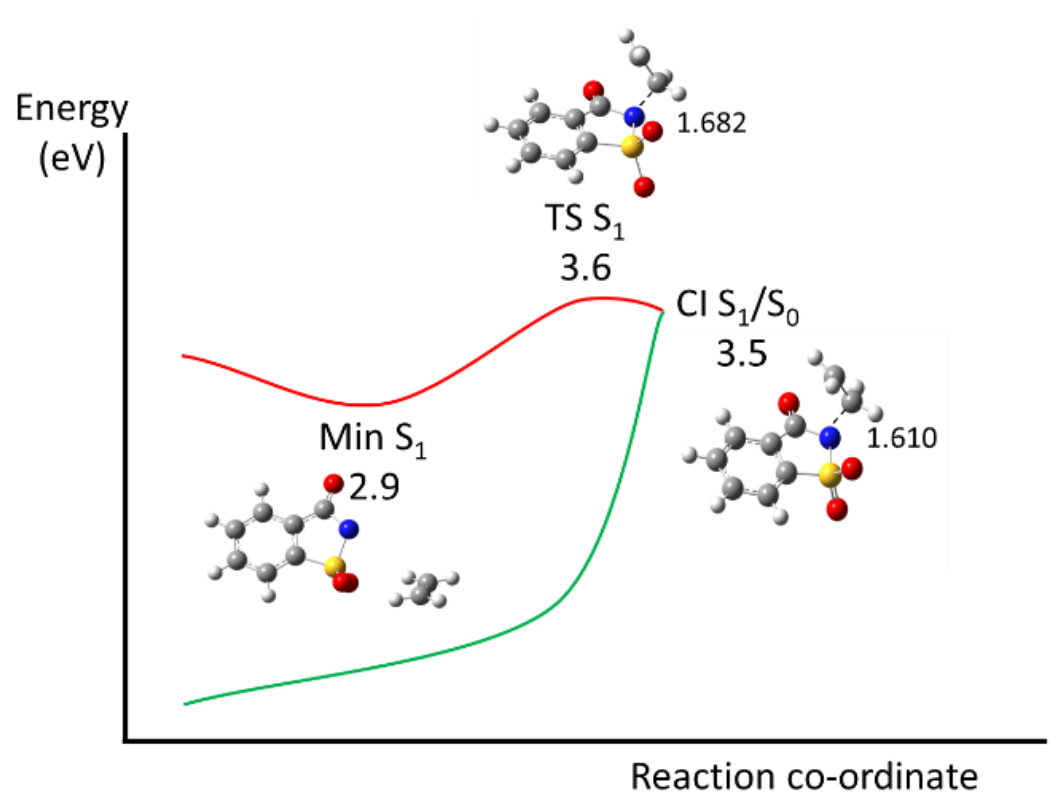

Figure 4. Critical points for the reaction of the saccharin anion with ethylene computed at the CASPT2 level.

Population of the $S_{1}$ minimum is independent from the presence of the unsaturated reagent (ethylene). Thus, we focused on the appearance of a new CI point responsible for the reactivity and its relative energy. As can be seen in Figure 4, a reactive CI point was found $1.6 \mathrm{eV}$ above the energy of the minimum. This CI point can be reached through a transition structure (TS) very similar in both energy and geometry and it is related to the interaction of one $\mathrm{C}$ atom in ethylene with the nitrogen atom in the saccharin anion (distance C-N 1.610 $)$. Analysis of the gradient difference and derivative coupling vectors (see Figure S5) reflects the elongation of the $\mathrm{C}=\mathrm{C}$ double bond in ethylene and the $\mathrm{C}-\mathrm{N}$ distance in the saccharin anion. At this point, population of the ground state takes place and the follow-up reaction, namely azetidine formation and ring opening, should happen along $\mathrm{S}_{0}$. Thus, while related reactions were reported to involve a [2+2] cycloaddition, ${ }^{13}$ in this case the proposed reaction mechanism implies the nucleophilic attack of the nitrogen atom in the saccharin anion to ethylene in the excited state with subsequent formation of the reaction products. Once reached the CI 
point, the population of the ground state could allow for the formation of the photoproducts by further shortening of the $\mathrm{C}-\mathrm{N}$ bond or recovery of the starting material by separation of the reactive species. In this latter case, light absorption would lead to an unsuccessful photoreaction, lowering the overall quantum yield and the efficiency of the photoreaction. This is in agreement with the long reaction times and the excess of alkene experimentally required. However, reagents will be ready for absorption of a new photon and eventually the photoreaction would occur. On the other hand, the formation of the photoproduct may take place from the CI geometry without the formation of any minimum or associated transition structure beyond the final product. That is, once the nucleophilic attack takes place in the excited state, a new C-C bond between the alkene $\alpha$ carbon and the carbonyl carbon atom with simultaneous ring expansion occurs in the ground state, directly leading to the photoproduct. The formal $[2+2]$ addition product is never found, in agreement with the experimental lack of evidence for the formation of azetidine derivatives. Interestingly, this could imply that related reactions may also elapse through a similar mechanism as shown here and not the claimed [2+2] cycloaddition with subsequent ring opening. At this stage, the experimental results together with computational modeling of the reaction accounts for a reaction mechanism close to path c, Scheme 3. However intermediates II and azetidine intermediate III were never found along the potential energy surface exploration (Scheme 4).

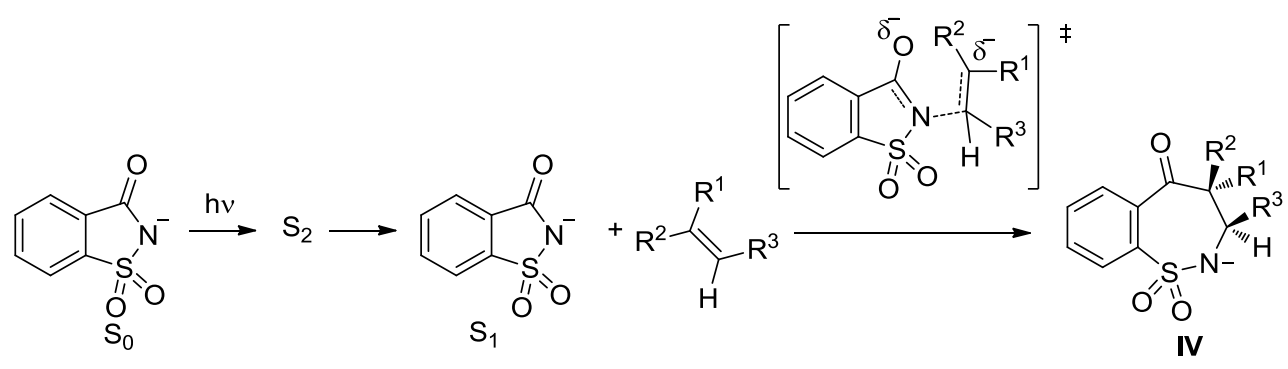

Scheme 4. Possible mechanism path to obtain benzosultams. 
Finally, the fate of the molecule after reaching the ground state and the observed regiochemistry was further explored by means of TD-DFT calculations, in order to include all the relevant atoms in the system. To check that TD-DFT could give qualitatively the same results than the more robust CASPT2 methodology, we reevaluated the critical points along the PES for the reaction between excites saccharin an $\alpha$-methyl-styrene shown in Figure 5 also at the B3LYP/6-3111++G** level (see Figure S6). While some geometrical features clearly differ, as expected for the different methods used, the overall qualitative shape of the PES is maintained for both levels of theory. It should be noted that TD-DFT cannot offer information on the CI geometry point, but the shape of the PES far from the state degeneracy region is clearly reproduced. Once validated, we used our TD-DFT model to explore the regiochemistry experimentally observed. In this case, the complete styrene system could be used, and two different nucleophilic attacks were computed, i.e., nitrogen atom attack to the $\alpha$ and $\beta$ carbons of styrene. Results are shown in Figure 5.

As can be seen, two alternative pathways were found for the reaction of the saccharin anion with styrene, namely the nucleophilic attack to the terminal $(\beta)$ or internal $(\alpha)$ positions of the alkene. Similar geometries for both TSs were found but a significant difference in energy between the two structures points to a kinetic preference for the attack of the nitrogen atom to the terminal carbon of the alkene. This may be due to both a smaller steric hindrance and a charge stabilization in the TS due to the neighboring phenyl ring, but in any case, the attack to the terminal carbon is clearly preferred. Once the TS is surmounted, the system would evolve through a geometrically and energetically close CI point (not shown) and would finally lead to the final photoproduct in the ground state. The clear difference in energy for both approaches is in agreement with the experimental results, as in all cases only one regioisomer was 
found. Interestingly, the obtained regioisomer is $c a .7 \mathrm{kcal} / \mathrm{mol}$ less stable than the alternative one. This confirms the kinetic control in the excited state, as the system will preferentially evolve through the smallest energy barrier (TS $\mathrm{S}_{1} \mathrm{~B}$ in Figure 5) which will define the product regiochemistry and subsequently go through the CI point and reach the ground state. From a synthetic point of view, this result also highlights the relevance of the photochemical process in order to get complex structures with a high degree of selectivity.
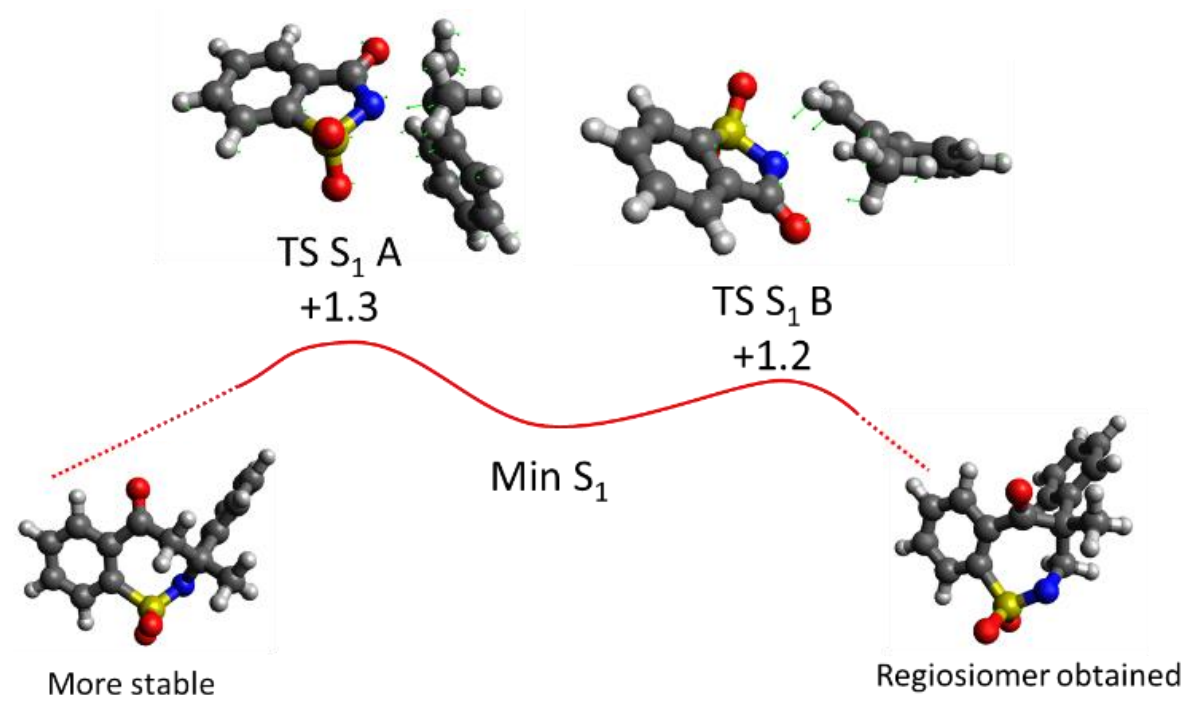

Figure 5. Minimum in the excited state, competitive transition structures with transition vectors and products for the reaction of the saccharin anion with $\alpha$-methyl styrene computed at the TD-DFT level.

\section{Conclusions}

We have explored the photoreactivity of saccharin anion with different alkene systems. Benzosultams were obtained in good yields in a regioselective way. This photocycloaddition approach was evaluated in order to stablish the potential synthesis of benzosultams at grame scale. Once more, photochemical reaction in flow proved to 
be better than standard batch reaction conditions, where a lower concentration of alkenes was used to prevent competitive photoreactions. This procedure involves operationally simpler reaction steps, faster reaction times, and significant improvements in the reaction scalability. A complementary computational study allowed to rationalize some experimental findings. The obtained mechanistic picture is different from other related reactions. A nucleophilic attack of the nitrogen atom in its excited state was found to control the reactivity and the regiochemistry of the reaction. The follow-up reactions take place in the ground state leading to the seven-member cyclic product without the mediation of the formal [2+2] cycloadduct.

\section{Experimental Section}

General methods: Irradiation was conducted in a commercial photoreactor RPR-100 $(16 \times 3000 \AA$ lamps, $\lambda=300 \pm 10 \mathrm{~nm}) .{ }^{1} \mathrm{H}$ and ${ }^{13} \mathrm{C}$ NMR spectra were registered on a $400 \mathrm{MHz}$ spectrometer and all spectra were reported in $\delta(\mathrm{ppm})$ relative to $\mathrm{Me}_{4} \mathrm{Si}$, with $\mathrm{CDCl}_{3}$ or $\mathrm{CD}_{3} \mathrm{OD}$ as solvents. Measurements were carried out using the standard pulse sequences. Gas chromatographic analyses were performed on a chromatograph with a flame-ionization detector, on $30 \mathrm{~m}$ capillary column of a $0.32 \mathrm{~mm} \times 0.25 \mu \mathrm{m}$ film thickness, with a 5\% phenylpolysiloxane phase. GC-MS analyses were performed on a spectrometer employing a $30 \mathrm{~m} \times 0.25 \mathrm{~mm} \times 0.25 \mu \mathrm{m}$ with a $5 \%$ phenylpolysiloxane phase column. Ionization was achieved by electronic impact (70eV) and detection setup positive mode. HRMS spectra were recorded on an orthogonal acceleration time-offlight (oa-TOF) mass spectrometer. IR spectra were obtained on infrared spectrometer. Melting points were obtained on melting point apparatus. 
Chemicals: Saccharin sodium salt hydrate, saccharin, $\alpha$-methyl-styrene, $\beta$-methylstyrene, styrene, p-methoxy-styrene, phenylacetylene, 1,1-diphenyletylene, methyl iodide, ((2-methylallyl)oxy)benzene were commercially available. Acetonitrile, Methanol (HPLC grade) were used as purchased without any further purification and

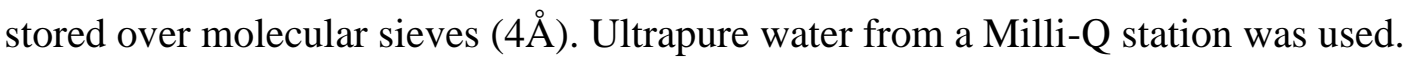

Spectroscopic Measurements: All measurements were carried out under inert atmosphere, in quartz cell, at room temperature. UV-vis spectra were recorded on a UVvis spectrophotometer and fluorescence spectra were performed in Fluorescence Spectrometer.

Computational Details. Theoretical calculations were performed with the GAUSSIAN $09^{16}$ and MOLCAS 8.0 suites of programs. ${ }^{17}$ The geometries of the critical points were computed using fully unconstrained $a b$ initio quantum chemical computations. This requires the reaction coordinate to be computed at the complete active space selfconsistent field (CASSCF) level of theory and the corresponding energy profile to be reevaluated at the complete active space perturbation theory to the second order (CASPT2) level of theory. Conical intersections have been located at the CASSCF level using the method developed by Bearpark et al. ${ }^{18}$ This method also provides the components of the branching space. The energy of the CASSCF geometries was recalculated using the CASPT2 method to take into account the effect of electron dynamic correlation. All CASPT2 results have been obtained with state average with equal weights for each state. Both CASSCF and CASPT2 calculations have been done using the standard 6-31G* basis set. Different active spaces were used depending on the structure computed. In all cases, the $\pi$ system was included (saccharin $3 \pi$ and $3 \pi^{*}$ orbitals from the phenyl ring, $\mathrm{C}=\mathrm{N}$ ) and the lone pairs of the nitrogen and oxygen atoms 
(active space of 12 electrons in 10 orbitals). The active space was increased to $(14,12)$ by addition of the $\mathrm{C}=\mathrm{C} \pi$ and $\pi^{*}$ orbitals of ethylene to compute the photoreaction.

For the DFT calculations, the B3LYP exchange-correlation functional together with the standard 6-31++G(d,p) basis set were used. The stationary points were located with the Berny algorithm ${ }^{19}$ using redundant internal coordinates. Analytical Hessians were computed to determine the nature of the stationary points.

\section{Representative experimental procedure for the photocycloaddition reaction in}

batch. A solution of saccharin sodium salt in methanol $(0.035 \mathrm{M}, 28 \mathrm{~mL}, 1 \mathrm{mmol})$ with 2 equivalent of $\mathrm{NaOH}(1 \mathrm{M})$ and 5 equivalents of alkene, was irradiated $(\lambda=300 \mathrm{~nm}, 8$ lamps in photo-reactor Rayonet, distance between lamps and reaction vessel of $10 \mathrm{~cm}$ ) in a Pyrex tube for $24 \mathrm{~h}$ while purged with a stream of nitrogen and cooled to $25{ }^{\circ} \mathrm{C}$. The reaction mixture was treated with an excess of a solution $\mathrm{HCl} 0.1 \mathrm{M}$. After removal of the solvent under reduced pressure, the residue was analyzed by GC and purified by column chromatography on silica gel using a mixture of pentane/ethyl acetate (70/30) as eluent.

\section{Representative experimental procedure for the photocycloaddition reaction in}

flow. A degassed solution of saccharin sodium salt $(0.05 \mathrm{M}, 20 \mathrm{~mL}, 1 \mathrm{mmol})$ with 2 equivalents of $\mathrm{NaOH}(0.1 \mathrm{M})$ in methanol together of 2 equivalents of alkene was continuously irradiated with $(\lambda=300 \mathrm{~nm}, 8$ lamps in photo-reactor Rayonet $)$ in a mesoscale photochemical flow reactor $(3.78 \mathrm{~mL}$ reactor volume, with $0.45 \mathrm{~mm}$ ID FEPtubing or $5.72 \mathrm{~mL}$ with $0.75 \mathrm{~mm}$ ID FEP-tubing) equipped with a Pyrex ${ }^{\circledR}$ filter at $25^{\circ} \mathrm{C}$. Finalized the reaction, it was treated with an excess of a solution $\mathrm{HCl} 0.1 \mathrm{M}$. When $\mathrm{ICH}_{3}$ was add, the solvent was remove under reduced pressure and $5 \mathrm{~mL}$ of DMF were added. After $2 \mathrm{~h}$, the mixture reaction was extracted with ethylacetate ( $3 \times 20 \mathrm{~mL})$. The 
organic extract was washed twice with water and dried over anhydrous $\mathrm{MgSO}_{4}$, and the products were purified by column chromatography on silica gel using a mixture of pentane/ethyl acetate (70/30) as eluent.

\section{Spectral information of all synthetized compounds}

4-methyl-4-phenyl-3,4-dihydrobenzo[f][1,2]thiazepin-5(2H)-one 1,1-dioxide (1a). Isolated as a white solid in a $71 \%$ yield $(214 \mathrm{mg}) ; \mathrm{mp} 208-210{ }^{\circ} \mathrm{C} .{ }^{1} \mathrm{H}$ NMR (400 $\left.\mathrm{MHz}, \mathrm{CD}_{3} \mathrm{OD}\right) \delta 7.78(\mathrm{dd}, J=7.5,1.3 \mathrm{~Hz}, 1 \mathrm{H}), 7.57-7.45(\mathrm{~m}, 2 \mathrm{H}), 7.42-7.35(\mathrm{~m}$, 1H), $7.31-7.24(\mathrm{~m}, 4 \mathrm{H}), 7.31-7.16(\mathrm{~m}, 1 \mathrm{H}), 4.10(\mathrm{~d}, J=15.4 \mathrm{~Hz}, 1 \mathrm{H}), 3.73(\mathrm{~d}, J=$ 15.4 Hz, 1H), 1.48 (s, 3H). ${ }^{13} \mathrm{C}\left\{{ }^{1} \mathrm{H}\right\}$ NMR (101 MHz, $\left.\mathrm{CD}_{3} \mathrm{OD}\right) \delta 205.5,139.6,138.5$, 136.6, 131.9, 130.8, 129.9, 128.3, 127.0, 126.7, 124.3, 57.6, 47.4, 23.8. IR (neat, $\mathrm{cm}^{-1}$ ) $3301(\mathrm{~N}-\mathrm{H} \mathrm{st}) ; 2985\left(\mathrm{C}_{\mathrm{sp}}{ }^{2}-\mathrm{H} \mathrm{st}\right) ; 2931\left(\mathrm{C}_{\mathrm{sp}}{ }^{3}-\mathrm{H} \mathrm{st}\right) ; 1692$ (C=O st); $1451\left(\mathrm{SO}_{2}\right.$ asym st), 1341 ( $\mathrm{SO}_{2}$ sym st); 1085 ( $\mathrm{S}=\mathrm{O}$ st); 900-700 ( $\mathrm{C}_{\mathrm{Ar}}-\mathrm{H}$ oop bending). HRMS (ESI-TOF) $\mathrm{m} / \mathrm{z}$ calcd for $\mathrm{C}_{16} \mathrm{H}_{15} \mathrm{NO}_{3} \mathrm{SNa}[\mathrm{M}+\mathrm{Na}]^{+}: 324.0665$ found: 324.0696 .

\section{2,4-dimethyl-4-phenyl-3,4-dihydrobenzo[f][1,2]thiazepin-5(2H)-one 1,1-dioxide} (1a'). Isolated as a yellowish solid in a 90\% yield (284 mg); mp $143-144{ }^{\circ} \mathrm{C} .{ }^{1} \mathrm{H}$ NMR $\left(400 \mathrm{MHz}, \mathrm{CDCl}_{3}\right) \delta 7.88-7.80(\mathrm{~m}, 1 \mathrm{H}), 7.57-7.49(\mathrm{~m}, 2 \mathrm{H}), 7.35-7.19(\mathrm{~m}, 6 \mathrm{H})$, $4.30(\mathrm{~d}, J=15.0 \mathrm{~Hz}, 1 \mathrm{H}), 3.37(\mathrm{~d}, J=15.0 \mathrm{~Hz}, 1 \mathrm{H}), 3.00(\mathrm{~s}, 3 \mathrm{H}), 1.60(\mathrm{~s}, 3 \mathrm{H}) .{ }^{13} \mathrm{C}\left\{{ }^{1} \mathrm{H}\right\}$ NMR $\left(101 \mathrm{MHz}, \mathrm{CDCl}_{3}\right) \delta 204.0,139.9,138.2,134.74$ 133.0, 130.7, 130.3, 128.5, 127.6, 127.1, 126.1, 58.6, 58.0, 37.8, 24.1. IR (neat, $\left.\mathrm{cm}^{-1}\right) 3087\left(\mathrm{C}_{\mathrm{sp}}{ }^{2}-\mathrm{H} \mathrm{st}\right) ; 2986\left(\mathrm{C}_{\mathrm{sp}}{ }^{3}-\right.$ H st); 1699 (C=O st); 1463 ( $\mathrm{SO}_{2}$ asym st); 1340 ( $\mathrm{SO}_{2}$ sym st); 1161 ( $\mathrm{S}=\mathrm{O}$ st); 900-700 $\left(\mathrm{C}_{\mathrm{Ar}}-\mathrm{H}\right.$ oop bending). HRMS (ESI-TOF) $\mathrm{m} / \mathrm{z}$ calcd for $\mathrm{C}_{17} \mathrm{H}_{17} \mathrm{NO}_{3} \mathrm{SNa}[\mathrm{M}+\mathrm{Na}]^{+}$: 338.0821; found: 338.0850 .

4-phenyl-3,4-dihydrobenzeno[f][1,2]thiazepin-5(2H)-one 1,1-dioxide (1b). Isolated as a white solid in a $15 \%$ yield $(43 \mathrm{mg}) ; \mathrm{mp} 121-123{ }^{\circ} \mathrm{C} .{ }^{1} \mathrm{H}$ NMR $\left(400 \mathrm{MHz}, \mathrm{CDCl}_{3}\right)$ 
$\delta 8.01-7.95(\mathrm{~m}, 1 \mathrm{H}), 7.61-7.55(\mathrm{~m}, 2 \mathrm{H}), 7.54-7.50(\mathrm{~m}, 1 \mathrm{H}), 7.36-7.28(\mathrm{~m}, 5 \mathrm{H})$, $5.61(\mathrm{~s}, 1 \mathrm{H}, \mathrm{N}-\mathrm{H}), 4.86(\mathrm{dd}, J=11.3,6.3 \mathrm{~Hz}, 1 \mathrm{H}), 3.86-3.59(\mathrm{~m}, 2 \mathrm{H}) .{ }^{13} \mathrm{C}\left\{{ }^{1} \mathrm{H}\right\} \mathrm{NMR}$ $\left(101 \mathrm{MHz}, \mathrm{CDCl}_{3}\right) \delta 201.2,140.6,137.4,134.6,132.6,131.6,129.13,129.05,128.8$, 128.2, 126.3, 57.6, 45.5. IR (neat, $\left.\mathrm{cm}^{-1}\right) 3294(\mathrm{~N}-\mathrm{H} \mathrm{st}) ; 3064\left(\mathrm{C}_{\mathrm{sp}}{ }^{2}-\mathrm{H} \mathrm{st}\right) ; 2927\left(\mathrm{C}_{\mathrm{sp}}{ }^{3}-\mathrm{H}\right.$ st); 1702 (C=O st); 1451 ( $\mathrm{SO}_{2}$ sym st); 1342 ( $\mathrm{SO}_{2}$ asym st); 1076 (S=O st); 900-700 $\left(\mathrm{C}_{\mathrm{Ar}}-\mathrm{H}\right.$ oop bending). HRMS (ESI-TOF) $\mathrm{m} / \mathrm{z}$ calcd for $\mathrm{C}_{15} \mathrm{H}_{14} \mathrm{NO}_{3} \mathrm{~S}[\mathrm{M}+\mathrm{H}]^{+}: 288.0688$; found: 288.0963 .

3-methyl-4-phenyl-3,4-dihydrobenzo[f][1,2]thiazepin-5(2H)-one 1,1-dioxide (1c). Isolated as a white solid in a $21 \%$ yield $(63 \mathrm{mg}) ; \mathrm{mp} 190-192{ }^{\circ} \mathrm{C} .{ }^{1} \mathrm{H}$ NMR (400 MHz, $\left.\mathrm{CDCl}_{3}\right) \delta 8.03(\mathrm{~d}, J=7.6 \mathrm{~Hz}, 1 \mathrm{H}), 7.65(\mathrm{t}, J=7.6 \mathrm{~Hz}, 1 \mathrm{H}), 7.59(\mathrm{t}, J=7.6 \mathrm{~Hz}, 1 \mathrm{H})$, $7.47(\mathrm{~d}, J=7.6 \mathrm{~Hz}, 1 \mathrm{H}), 7.37-7.33(\mathrm{~m}, 3 \mathrm{H}), 7.31-7.29(\mathrm{~m}, 2 \mathrm{H}), 5.26(\mathrm{~d}, J=6.6 \mathrm{~Hz}$, $1 \mathrm{H}), 4.74(\mathrm{~d}, J=11.5 \mathrm{~Hz}, 1 \mathrm{H}), 4.01-3.88(\mathrm{~m}, 1 \mathrm{H}), 1.32(\mathrm{~d}, J=6.6 \mathrm{~Hz}, 3 \mathrm{H}) .{ }^{13} \mathrm{C}\left\{{ }^{1} \mathrm{H}\right\}$ NMR (101 MHz, $\left.\mathrm{CDCl}_{3}\right) \delta 200.8,141.5,136.8,135.0,132.4,131.7,129.2,129.1$, 128.8, 128.2, 126.1, 64.1, 53.1, 21.2. IR (neat, $\left.\mathrm{cm}^{-1}\right) 3274(\mathrm{~N}-\mathrm{H} \mathrm{st}) ; 3062\left(\mathrm{C}_{\mathrm{sp}}{ }^{2}-\mathrm{H} \mathrm{st}\right)$; $2982\left(\mathrm{C}_{\mathrm{sp}}{ }^{3}-\mathrm{H} \mathrm{st}\right) ; 1691(\mathrm{C}=\mathrm{O} \mathrm{st}) ; 1448\left(\mathrm{SO}_{2}\right.$ asym st $) ; 1308\left(\mathrm{SO}_{2}\right.$ sym st $) ; 1085(\mathrm{~S}=\mathrm{O}$ st); 900-700 ( $\mathrm{C}_{\mathrm{Ar}}-\mathrm{H}$ oop bending). HRMS (ESI-TOF) $\mathrm{m} / \mathrm{z}$ calcd for $\mathrm{C}_{16} \mathrm{H}_{15} \mathrm{NO}_{3} \mathrm{SNa}$ $[\mathrm{M}+\mathrm{Na}]^{+}:$324.0665; found: 324.0693 .

\section{2-(1-(4-methoxyphenyl)ethyl)benzo[d]isothiazol-3(2H)-one $\quad$ 1,1-dioxide $\quad$ (1d).}

Isolated as a yellowish solid in a $13 \%$ yield (41 mg); mp $222-224{ }^{\circ} \mathrm{C} .{ }^{1} \mathrm{H}$ NMR (400 $\left.\mathrm{MHz}_{\mathrm{CDCl}}\right) \delta 7.96(\mathrm{~d}, J=7.1 \mathrm{~Hz}, 1 \mathrm{H}), 7.88(\mathrm{~d}, J=7.2 \mathrm{~Hz}, 1 \mathrm{H}), 7.82(\mathrm{td}, J=7.5,1.2$ $\mathrm{Hz}, 1 \mathrm{H}), 7.80-7.73(\mathrm{~m}, 1 \mathrm{H}), 7.53(\mathrm{~d}, J=8.2 \mathrm{~Hz}, 2 \mathrm{H}), 6.87(\mathrm{t}, J=8.2 \mathrm{~Hz}, 2 \mathrm{H}), 5.42(\mathrm{q}$, $J=7.3 \mathrm{~Hz}, 1 \mathrm{H}), 3.79(\mathrm{~s}, 3 \mathrm{H}), 2.00(\mathrm{~d}, J=7.3 \mathrm{~Hz}, 3 \mathrm{H}) .{ }^{13} \mathrm{C}\left\{{ }^{1} \mathrm{H}\right\}$ NMR $(101 \mathrm{MHz}$, $\left.\mathrm{CDCl}_{3}\right) \delta 159.4,158.5,137.8,134.6,134.1,130.6,129.1,127.4,125.0,120.7,113.8$, 55.2, 52.6, 17.8. IR (neat, $\left.\mathrm{cm}^{-1}\right) 3090\left(\mathrm{C}_{\mathrm{sp}}{ }^{2}-\mathrm{H} \mathrm{st}\right) ; 2916\left(\mathrm{C}_{\mathrm{sp}}{ }^{3}-\mathrm{H} \mathrm{st}\right) ; 1729(\mathrm{C}=\mathrm{O} \mathrm{st}) ; 1455$ ( $\mathrm{SO}_{2}$ asym st); 1329 ( $\mathrm{SO}_{2}$ sym st); 1109 (C-O-C st); 1063 (S=O st); 900-700 (C $\mathrm{C}_{\mathrm{Ar}}-\mathrm{H}$ oop 
bending). HRMS (ESI-TOF) m/z calcd for $\mathrm{C}_{16} \mathrm{H}_{15} \mathrm{NO}_{4} \mathrm{SNa}[\mathrm{M}+\mathrm{Na}]^{+}:$340.0614; found: 340.0608 .

4,4-diphenyl-3,4-dihydrobenzo[f][1,2]thiazepin-5(2H)-one 1,1-dioxide (1e). Isolated as a white solid in a $30 \%$ yield $(109 \mathrm{mg}), \mathrm{mp} 212-213{ }^{\circ} \mathrm{C} .{ }^{1} \mathrm{H}$ NMR $\left(400 \mathrm{MHz}, \mathrm{CDCl}_{3}\right)$ $\delta 7.72(\mathrm{~d}, J=7.7 \mathrm{~Hz}, 1 \mathrm{H}), 7.49(\mathrm{td}, J=7.7,1.2 \mathrm{~Hz}, 1 \mathrm{H}), 7.45(\mathrm{td}, J=7.7,1.2 \mathrm{~Hz}, 1 \mathrm{H})$, $7.41-7.28(\mathrm{~m}, 7 \mathrm{H}), 7.07(\mathrm{~d}, J=6.9 \mathrm{~Hz}, 4 \mathrm{H}), 5.37(\mathrm{t}, J=6.3 \mathrm{~Hz}, 1 \mathrm{H}), 4.34(\mathrm{~d}, J=6.3$ $\mathrm{Hz}, 2 \mathrm{H}) .{ }^{13} \mathrm{C}\left\{{ }^{1} \mathrm{H}\right\}$ NMR $\left(101 \mathrm{MHz}, \mathrm{CDCl}_{3}\right) \delta 201.8,138.6,137.9,136.4,132.9,132.5$, 130.9, 129.0, 128.8, 128.1, 125.8, 68.0, 48.5. IR (neat, $\left.\mathrm{cm}^{-1}\right) 3298(\mathrm{~N}-\mathrm{H} \mathrm{st}) ; 3094,3060$, $3020\left(\mathrm{C}_{\mathrm{sp}}{ }^{2}-\mathrm{H}\right.$ st $) ; 2941\left(\mathrm{C}_{\mathrm{sp}}{ }^{3}-\mathrm{H}\right) ; 1686(\mathrm{C}=\mathrm{O} \mathrm{st}) ; 1448\left(\mathrm{SO}_{2}\right.$ asym st); 1345 ( $\left.\mathrm{SO}_{2} \mathrm{sym} \mathrm{st}\right)$; 1090 ( $\mathrm{S}=\mathrm{O}$ st); $900-700\left(\mathrm{C}_{\mathrm{Ar}}-\mathrm{H}\right.$ oop bending). HRMS (ESI-TOF) $\mathrm{m} / \mathrm{z}$ calcd for $\mathrm{C}_{21} \mathrm{H}_{17} \mathrm{NNaO}_{3} \mathrm{~S}[\mathrm{M}+\mathrm{Na}]^{+}: 386.0821$; found: 386.0826 .

2-methyl-4,4-diphenyl-3,4-dihydrobenzo[f][1,2]thiazepin-5(2H)-one 1,1-dioxide (1e'). Isolated as a yellowish solid in an $84 \%$ yield $(317 \mathrm{mg}) ; \mathrm{mp} 103-105{ }^{\circ} \mathrm{C} .{ }^{1} \mathrm{H}$ NMR (400 MHz, $\left.\mathrm{CDCl}_{3}\right) \delta 7.93(\mathrm{~d}, J=7.8 \mathrm{~Hz}, 1 \mathrm{H}), 7.56(\mathrm{~d}, J=7.6 \mathrm{~Hz}, 1 \mathrm{H}), 7.49(\mathrm{t}, J$ $=7.6 \mathrm{~Hz}, 1 \mathrm{H}), 7.34-7.24(\mathrm{~m}, 7 \mathrm{H}), 7.23-7.13(\mathrm{~m}, 4 \mathrm{H}), 4.20(\mathrm{~s}, 2 \mathrm{H}), 2.77(\mathrm{~s}, 3 \mathrm{H})$. ${ }^{13} \mathrm{C}\left\{{ }^{1} \mathrm{H}\right\} \mathrm{NMR}\left(101 \mathrm{MHz}, \mathrm{CDCl}_{3}\right) \delta 201.3,140.3,136.5,135.6,132.8,131.9,131.3$, 129.1, 128.5, 127.8, 126.2, 67.2, 57.5, 35.9. IR (neat, $\left.\mathrm{cm}^{-1}\right) 3094,3063,3029\left(\mathrm{C}_{\mathrm{sp}}{ }^{2}-\mathrm{H}\right.$ st); $2943\left(\mathrm{C}_{\mathrm{sp}}{ }^{3}-\mathrm{H}\right.$ st); 1692 (C=O st); $1448\left(\mathrm{SO}_{2}\right.$ asym st); $1343\left(\mathrm{SO}_{2}\right.$ sym st); 1056 $\left(\mathrm{S}=\mathrm{O}\right.$ st); 900-700 ( $\mathrm{C}_{\mathrm{Ar}}-\mathrm{H}$ oop bending). HRMS (ESI-TOF) $\mathrm{m} / \mathrm{z}$ calcd for $\mathrm{C}_{22} \mathrm{H}_{19} \mathrm{NO}_{3} \mathrm{SNa}[\mathrm{M}+\mathrm{Na}]^{+}: 400.0978$; found: 400.0989 .

4-phenylbenzo[f][1,2]thiazepin-5(2H)-one 1,1-dioxide (1f). Isolated as a white solid in a $7 \%$ yield $(20 \mathrm{mg}) ; 106-108{ }^{\circ} \mathrm{C} .{ }^{1} \mathrm{H}$ NMR $\left(400 \mathrm{MHz}, \mathrm{CDCl}_{3}\right) \delta 7.93(\mathrm{~d}, J=7.6 \mathrm{~Hz}$, 1H), $7.89(\mathrm{~d}, J=7.4 \mathrm{~Hz}, 1 \mathrm{H}), 7.78(\mathrm{t}, J=7.5 \mathrm{~Hz}, 1 \mathrm{H}), 7.73(\mathrm{t}, J=7.5 \mathrm{~Hz}, 1 \mathrm{H}), 7.40-$ $7.29(\mathrm{~m}, 5 \mathrm{H}), 6.89(\mathrm{~s}, 1 \mathrm{H}) .{ }^{13} \mathrm{C}\left\{{ }^{1} \mathrm{H}\right\} \mathrm{NMR}\left(101 \mathrm{MHz}, \mathrm{CDCl}_{3}\right) \delta 191.9$ (HMBC), 138.6, $137.4,136.1,134.2,132.3,132.0,130.6,129.9,128.5,128.1,126.1,123.3$. IR (neat, 
$\left.\mathrm{cm}^{-1}\right) 3250(\mathrm{~N}-\mathrm{H} \mathrm{st}) ; 3065\left(\mathrm{C}_{\mathrm{sp}}{ }^{2}-\mathrm{H} \mathrm{st}\right) ; 2952\left(\mathrm{C}_{\mathrm{sp}}{ }^{3}-\mathrm{H} \mathrm{st}\right) ; 1467\left(\mathrm{SO}_{2}\right.$ asym st); $1337\left(\mathrm{SO}_{2}\right.$ sym st); 1090 ( $\mathrm{S}=\mathrm{O}$ st); 900-700 ( $\mathrm{C}_{\mathrm{Ar}}-\mathrm{H}$ oop bending). HRMS (ESI-TOF) m/z calcd for $\mathrm{C}_{15} \mathrm{H}_{12} \mathrm{NO}_{3} \mathrm{~S}[\mathrm{M}+\mathrm{H}]^{+}:$286.05324; found: 286.0521 .

2-methyl-4-phenylbenzo[f][1,2]thiazepin-5(2H)-one 1,1-dioxide (1f'). Isolated as a yellow solid in a $39 \%$ yield $(117 \mathrm{mg}) ; \mathrm{mp} 154-156{ }^{\circ} \mathrm{C} .{ }^{1} \mathrm{H}$ NMR $\left(400 \mathrm{MHz}, \mathrm{CDCl}_{3}\right) \delta$ $7.92(\mathrm{dd}, J=7.3,1.6,1 \mathrm{H}), 7.90(\mathrm{dd}, J=7.3,1.6,1 \mathrm{H}), 7.79(\mathrm{td}, J=7.4,1.6 \mathrm{~Hz}, 1 \mathrm{H})$, $7.74(\mathrm{td}, J=7.3,1.4 \mathrm{~Hz}, 1 \mathrm{H}), 7.39-7.31(\mathrm{~m}, 5 \mathrm{H}), 6.83(\mathrm{~s}, 1 \mathrm{H}), 3.40(\mathrm{~s}, 3 \mathrm{H}) .{ }^{13} \mathrm{C}\left\{{ }^{1} \mathrm{H}\right\}$ NMR $\left(101 \mathrm{MHz}, \mathrm{CDCl}_{3}\right) \delta 186.9,138.5,138.4,137.6,135.2,134.0,131.9,130.3$, 129.9, 128.3, 127.9, 126.5, 123.9, 38.7. IR (neat, $\left.\mathrm{cm}^{-1}\right) 3065\left(\mathrm{C}_{\mathrm{sp}}{ }^{2}-\mathrm{H} \mathrm{st}\right) ; 2941\left(\mathrm{C}_{\mathrm{sp}}{ }^{3}-\mathrm{H}\right.$ st); 1734 (C=O st); 1442 ( $\mathrm{SO}_{2}$ asym st); 1345 ( $\mathrm{SO}_{2}$ sym st); 1064 ( $\mathrm{S}=\mathrm{O}$ st); $900-700$ $\left(\mathrm{C}_{\mathrm{Ar}}-\mathrm{H}\right.$ oop bending). HRMS (ESI-TOF) $\mathrm{m} / \mathrm{z}$ calcd for $\mathrm{C}_{16} \mathrm{H}_{13} \mathrm{NO}_{3} \mathrm{SNa}[\mathrm{M}+\mathrm{Na}]^{+}$: 322.0508; found: 322.0528 .

6a,7,8,9,10,10a-hexahydrodibenzo $[c, f][1,2]$ thiazepin-11(6H)-one 5,5 -dioxide (1g). Isolated as a white solid in a $5 \%$ yield $(13 \mathrm{mg}) ; 184-186{ }^{\circ} \mathrm{C} .{ }^{1} \mathrm{H}$ NMR $(400 \mathrm{MHz}$, $\left.\mathrm{CDCl}_{3}\right) \delta 7.97(\mathrm{dd}, J=5.8,3.1 \mathrm{~Hz}, 1 \mathrm{H}), 7.67-7.61(\mathrm{~m}, 1 \mathrm{H}), 7.61-7.53(\mathrm{~m}, 2 \mathrm{H}), 5.10$ $(\mathrm{d}, J=5.9 \mathrm{~Hz}, 1 \mathrm{H}), 3.44(\mathrm{td}, J=11.3,3.3 \mathrm{~Hz}, 1 \mathrm{H}), 3.27-3.17(\mathrm{~m}, 1 \mathrm{H}), 2.15(\mathrm{dd}, J=$ 13.0, 3.1 Hz, 1H), $1.93-1.72(\mathrm{~m}, 5 \mathrm{H}), 1.40-1.18(\mathrm{~m}, 2 \mathrm{H}) .{ }^{13} \mathrm{C}\left\{{ }^{1} \mathrm{H}\right\} \mathrm{NMR}(101 \mathrm{MHz}$, $\left.\mathrm{CDCl}_{3}\right) \delta 203.0,141.4,137.4,132.5,131.5,129.1,126.0,55.8,55.0,34.8,27.2,25.3$, 24.0. IR (neat, $\left.\mathrm{cm}^{-1}\right) 3244\left(\mathrm{~N}-\mathrm{H}\right.$ st); $3071\left(\mathrm{C}_{\mathrm{sp}}{ }^{2}-\mathrm{H} \mathrm{st}\right) ; 2926\left(\mathrm{C}_{\mathrm{sp}}{ }^{2}-\mathrm{H} \mathrm{st}\right) ; 1672(\mathrm{C}=\mathrm{O} \mathrm{st})$; 1439 ( $\mathrm{SO}_{2}$ asym st); 1328 ( $\mathrm{SO}_{2}$ sym st); 1070 ( $\mathrm{S}=\mathrm{O}$ st); 900-700 ( $\mathrm{C}_{\mathrm{Ar}}-\mathrm{H}$ oop bending). HRMS (ESI-TOF) m/z calcd for $\mathrm{C}_{13} \mathrm{H}_{15} \mathrm{NO}_{3} \mathrm{SNa}$ [M+Na] $]^{+}: 288.0665$; found: 288.0668.

\section{6,10a-dimethyl-6a,7,8,9,10,10a-hexahydrodibenzo $[c, f][1,2]$ thiazepin-11(6H)-one}

5,5-dioxide (1h'). Isolated as a white solid in a 55\% yield (161 mg); mp $166-168{ }^{\circ} \mathrm{C}$. ${ }^{1} \mathrm{H}$ NMR $\left(400 \mathrm{MHz}, \mathrm{CDCl}_{3}\right) \delta 7.89(\mathrm{dd}, J=7.8,1.1 \mathrm{~Hz}, 1 \mathrm{H}), 7.59(\mathrm{td}, J=7.6,1.5 \mathrm{~Hz}$, 1H), $7.54(\mathrm{td}, J=7.7,1.6 \mathrm{~Hz}, 1 \mathrm{H}), 7.38(\mathrm{dd}, J=7.2,1.1 \mathrm{~Hz}, 1 \mathrm{H}), 3.27-3.22(\mathrm{~m}, 1 \mathrm{H})$, 
$3.16(\mathrm{~s}, 3 \mathrm{H}), 2.30-2.14(\mathrm{~m}, 2 \mathrm{H}), 2.04-1.82(\mathrm{~m}, 3 \mathrm{H}), 1.60-1.53(\mathrm{~m}, 1 \mathrm{H}), 1.37-1.23$ (m, 2H), 1.09 (s, 3H). ${ }^{13} \mathrm{C}\left\{{ }^{1} \mathrm{H}\right\} \mathrm{NMR}\left(101 \mathrm{MHz}, \mathrm{CDCl}_{3}\right) \delta 206.6,138.6,136.4,132.8$, $130.3,129.3,126.0,68.5,54.0,39.5,36.9,30.2,27.7,26.2,22.6$. IR (neat, $\mathrm{cm}^{-1}$ ) 3088 $\left(\mathrm{C}_{\mathrm{sp}}{ }^{2}-\mathrm{H} \mathrm{st}\right) ; 2932\left(\mathrm{C}_{\mathrm{sp}}{ }^{3}-\mathrm{H} \mathrm{st}\right) ; 1697$ (C=O st); 1453 ( $\mathrm{SO}_{2}$ asym st); 1334 ( $\mathrm{SO}_{2}$ sym st); $1104(\mathrm{~S}=\mathrm{O})$; 900-700 ( $\mathrm{C}_{\mathrm{Ar}}-\mathrm{H}$ oop bending). HRMS (ESI-TOF) $\mathrm{m} / \mathrm{z}$ calcd for $\mathrm{C}_{15} \mathrm{H}_{19} \mathrm{NO}_{3} \mathrm{~S}[\mathrm{M}+\mathrm{H}]^{+}:$294.1158; found: 294.1182 .

10a-phenyl-6a,7,8,9,10,10a-hexahydrodibenzo $[c, f][1,2]$ thiazepin-11(6H)-one $\quad 5,5-$ dioxide (1i). Isolated as a white solid in a $20 \%$ yield $(68 \mathrm{mg}) ; \mathrm{mp} 220-222{ }^{\circ} \mathrm{C} .{ }^{1} \mathrm{H}$ NMR (400 MHz, $\left.\mathrm{CDCl}_{3}\right) \delta 7.96(\mathrm{~d}, J=7.3 \mathrm{~Hz}, 1 \mathrm{H}), 7.59(\mathrm{t}, J=7.3 \mathrm{~Hz}, 1 \mathrm{H}), 7.40(\mathrm{t}, J=$ $7.3 \mathrm{~Hz}, 1 \mathrm{H}), 7.34-7.24(\mathrm{~m}, 3 \mathrm{H}), 7.20(\mathrm{~d}, J=7.3 \mathrm{~Hz}, 2 \mathrm{H}), 6.73(\mathrm{~d}, J=7.7 \mathrm{~Hz}, 1 \mathrm{H})$, $5.32(\mathrm{~d}, J=10.5 \mathrm{~Hz}, 1 \mathrm{H}), 4.61(\mathrm{~d}, J=9.8 \mathrm{~Hz}, 1 \mathrm{H}), 2.90(\mathrm{~d}, J=15.3 \mathrm{~Hz}, 1 \mathrm{H}), 2.01\left({ }_{\mathrm{br}} \mathrm{d}\right.$, $J=14.4 \mathrm{~Hz}, 1 \mathrm{H}), 1.95-1.79(\mathrm{~m}, 2 \mathrm{H}), 1.73\left({ }_{\mathrm{br}} \mathrm{d}, J=13.3 \mathrm{~Hz}, 1 \mathrm{H}\right), 1.65\left(_{\mathrm{br}} \mathrm{d}, J=13.3\right.$ $\mathrm{Hz}, 1 \mathrm{H}), 1.40(\mathrm{~m}, 1 \mathrm{H}), 1.15(\mathrm{~m}, 1 \mathrm{H}) .{ }^{13} \mathrm{C}\left\{{ }^{1} \mathrm{H}\right\} \mathrm{NMR}\left(101 \mathrm{MHz}, \mathrm{CDCl}_{3}\right) \delta 204.7,138.1$, $135.8,134.8,132.8,131.7,130.7,129.3,128.0,127.43,127.42,60.5,51.0,29.2,28.0$, 20.9, 20.5. IR (neat, $\left.\mathrm{cm}^{-1}\right) 3256(\mathrm{~N}-\mathrm{H} \mathrm{st}) ; 2924\left(\mathrm{C}_{\mathrm{sp}}{ }^{3}-\mathrm{H} \mathrm{st}\right) ; 1686(\mathrm{C}=\mathrm{O} \mathrm{st}) ; 1445\left(\mathrm{SO}_{2}\right.$ asym st); 1297 ( $\mathrm{SO}_{2}$ sym st); 1162 ( $\mathrm{S}=\mathrm{O}$ st); 900-700 ( $\mathrm{C}_{\mathrm{Ar}}-\mathrm{H}$ oop bending). HRMS (ESI-TOF) $\mathrm{m} / \mathrm{z}$ calcd for $\mathrm{C}_{19} \mathrm{H}_{19} \mathrm{NO}_{3} \mathrm{SNa}[\mathrm{M}+\mathrm{Na}]^{+}:$: 364.0978; found: 364.0996 .

\section{2,4-dimethyl-4-(phenoxymethyl)-3,4-dihydrobenzo[f][1,2] thiazepin-5(2H)-one 1,1-}

dioxide (1j'). Isolated as a colorless oil in a 60\% yield (207 mg). ${ }^{1} \mathrm{H}$ NMR (400 MHz, $\left.\mathrm{CDCl}_{3}\right) \delta 7.94-7.80(\mathrm{~m}, 1 \mathrm{H}), 7.56(\mathrm{~m}, 2 \mathrm{H}), 7.46-7.36(\mathrm{~m}, 1 \mathrm{H}), 7.25(\mathrm{t}, J=7.8 \mathrm{~Hz}$, 2H), $6.95(\mathrm{t}, J=7.8 \mathrm{~Hz}, 1 \mathrm{H}), 6.78(\mathrm{~d}, J=7.8 \mathrm{~Hz}, 2 \mathrm{H}), 4.03(\mathrm{~d}, J=9.1 \mathrm{~Hz}, 1 \mathrm{H}), 3.96(\mathrm{~d}$, $J=9.1 \mathrm{~Hz}, 1 \mathrm{H}), 3.75(\mathrm{~d}, J=15.0 \mathrm{~Hz}, 1 \mathrm{H}), 3.60(\mathrm{~d}, J=15.0 \mathrm{~Hz}, 1 \mathrm{H}), 3.01(\mathrm{~s}, 3 \mathrm{H}), 1.38$ (s, 3H). ${ }^{13} \mathrm{C}\left\{{ }^{1} \mathrm{H}\right\}$ NMR $\left(101 \mathrm{MHz}, \mathrm{CDCl}_{3}\right) \delta 204.8,158.2,138.4,134.5,133.1,130.5$, 129.6, 129.3, 126.2, 121.6, 114.5, 71.2, 56.0, 54.5, 38.4, 19.1. IR (neat, $\mathrm{cm}^{-1}$ ) 3063 (Csp2-H st); 2935 (Csp3-H st); 1697 (C=O st); 1467 ( $\mathrm{SO}_{2}$ asym st); 1343 ( $\mathrm{SO}_{2}$ sym st); 
1039 ( $\mathrm{S}=\mathrm{O}$ st); 900-700 ( $\mathrm{C}_{\mathrm{Ar}}-\mathrm{H}$ oop bending). HRMS (ESI-TOF) $\mathrm{m} / \mathrm{z}$ calcd for $\mathrm{C}_{18} \mathrm{H}_{19} \mathrm{NO}_{4} \mathrm{SNa}[\mathrm{M}+\mathrm{Na}]^{+}:$368.0927; found: 368.0929.

\section{Acknowledgements}

This work was supported in part by Consejo Nacional de Investigaciones Científicas y Técnicas (CONICET), Secretaría de Ciencia y Tecnología (SeCyT), Universidad Nacional de Córdoba (UNC), Fondo para la Investigación Científica y Tecnológica Argentina (FONCyT) and Spanish Ministerio de Economía y Competitividad (CTQ2017-87372-P). FF and AH gratefully acknowledge receipt of a fellowship from CONICET.

\section{Supporting Information}

${ }^{1} \mathrm{H}$ NMR and ${ }^{13} \mathrm{C}$ NMR for all compounds, continuous photo-flow setup, photophysical study, cartesian coordinates for the computed structures. This material is available free of charge via the Internet at http://pubs.acs.org.

\section{References}

(1) (a) Ilardi, E. A.; Vitaku, E.; Njardarson, J. T. Data-mining for sulfur and fluorine: an evaluation of pharmaceuticals to reveal opportunities for drug design and discovery $J$. Med. Chem. 2014, 57, 2832-2842. (b) Kalgutkar, A. S.; Jones, R.; Sawant, A. Chapter 5. Sulfonamide as an essential functional group in drug design. Metabolism, pharmacokinetics and toxicity of functional ggroups: impact of chemical building blocks on ADMET. D. A. Smith Eds. 210-270. 2010.

(2) (a) Majumdar, K. C.; Mondal, S. Recent developments in the synthesis of fused sultams Chem. Rev. 2011, 111, 7749-7773. (b) Tang, X.; Li, Z.; Li, Y.; Liu, W.; Yu, P.; Li, L.; Guo, Y.; Yang, C. Synthesis and biological evaluation of novel saccharin 
derivatives containing 1,2,3-triazole moiety Chem. Res. Chin. Univ. 2015, 31, 71-77. (c) Majumdar, S.; Juntunen, J.; Sivendran, S.; Bharti, N.; Sloan, K. B. Synthesis of soft alkyl phenolic ether prodrugs using Mitsunobu chemistry Tetrahedron Lett. 2006, 47, 8981-8982. (d) Csakai, A.; Smith, C.; Davis, E.; Martinko, A.; Coulup, S.; Yin, H. Saccharin derivatives as inhibitors of interferon-mediated inflammation $\mathrm{J}$. Med. Chem. 2014, 57, 5348-5355.

(3) (a) Laha, J. K.; Bhimpuria, R. A.; Kumar, A. M. Post-synthetic diversification of pyrrole fused benzosultams via trans-sulfonylations and reactions on the periphery of pyrrole Org. Chem. Front. 2017, 4, 2170-2174. (b) Fawad-Zahoor, A.; Akhtar, R.; Ahmad, S.; Ali-Raza Naqvi, S.; Gul-Khan, S.; Suleman, M. Update on the reactivity of saccharin: an excellent precursor for the synthesis of biologically important molecules Heterocycles 2017, 94, 1389-1426. (c) Debnath, S.; Mondal, S. Sultams: Recent Syntheses and Applications Eur. J. Org. Chem. 2018, 2018, 933-956.

(4) Döpp, D. The surprising photochemistry of sultams related to saccharin Int. J. Photoenergy 2001, 3, 41-48.

(5) (a) Kamigata, N.; Saegusa, T.; Fujie, S.-i.; Kobayashi, M. Photochemical reactions on $N$-alkyl and $N$-allyl-o-sulfobenzimides Chem. Lett. 1979, 9-12. (b) Yoon, U. C.; Koh, Y. S.; Kim, H. J.; Jung, D. Y.; Kim, D. U.; Cho, S. J.; Lee, S. J. Photochemical Reactions of Saccharin-a-Silylamine Systems. Desilylmethylation of a-Silylamine via Single Electron Transfer Pathway. Bull. Korean Chem. Soc. 1994, 15, 743-748.

(6) Cho, D.-W.; Oh, S.-W.; Kim, D.-U.; Park, H.-J.; Xue, J.-Y.; Yoon, U.-C.; Mariano, P. S. Studies of silyl-transfer photochemical reactions of $N$ [(trimethylsilyl)alkyl]saccharins Bull. Korean Chem. Soc. 2010, 31, 2453-2458.

(7) Castro-Godoy, W. D.; Oksdath-Mansilla, G.; Arguello, J. E.; Penenory, A. B. Exploring the photophysical and photochemical properties of $N$-(thioalkyl)-saccharins 
as an alternative route to the synthesis of tricyclic sultams J. Org. Chem. 2017, 82, 101108.

(8) Ganguly, A. K.; Alluri, S. S.; Caroccia, D.; Biswas, D.; Wang, C. H.; Kang, E.; Zhang, Y.; McPhail, A. T.; Carroll, S. S.; Burlein, C.; Munshi, V.; Orth, P.; Strickland, C. Design, synthesis, and X-ray crystallographic analysis of a novel class of HIV-1 protease inhibitors J. Med. Chem. 2011, 54, 7176-7183.

(9) Rayabarapu, D. K.; Zhou, A.; Jeon, K. O.; Samarakoon, T.; Rolfe, A.; Siddiqui, H.; Hanson, P. R. a-Haloarylsulfonamides: multiple cyclization pathways to skeletally diverse benzofused sultams Tetrahedron 2009, 65, 3180-3188.

(10) (a) Cambié, D.; Bottecchia, C.; Straathof, N. J.; Hessel, V.; Noël, T. Applications of continuous-flow photochemistry in organic synthesis, material science, and water treatment Chem Rev 2016, 116, 10276-10341. (b) Elliott, L. D.; Knowles, J. P.; Stacey, C. S.; Klauberb, D. J.; Booker-Milburn, K. I. Using batch reactor results to calculate optimal flow rates for the scale-up of UV photochemical reactions React. Chem. Eng. 2018, 3, 86-93. (c) Kuijpers, K. P. L.; van Dijk, M. A. H.; Rumeur, Q. G.; Hessel, V.; Su, Y.; Noël, T. A sensitivity analysis of a numbered-up photomicroreactor system Reac. Chem. Eng. 2017, 2, 109-115.

(11) Politano, F.; Oksdath-Mansilla, G. Light on the horizon: current research and future perspectives in flow photochemistry Org. Process. Res. Dev. 2018, 22, 10451062.

(12) (a) Porta, R.; Benaglia, M.; Puglisi, A. Flow chemistry: recent developments in the synthesis of pharmaceutical products Org. Process. Res. Dev. 2016, 20, 2-25. (b) Lima, F.; Grunenberg, L.; Rahman, H. B. A.; Labes, R.; Sedelmeier, J.; Ley, S. V. Organic photocatalysis for the radical couplings of boronic acid derivatives in batch and flow Chem. Commun. 2018, 54, 5606-5609. 
(13) Suau, R.; Sánchez-Sánchez, C.; García-Segura, R.; Pérez-Inestrosa, E. Photocycloaddition of phthalimide anion to alkenes - A highly efficient, convergent method for [2]benzazepine synthesis Eur. J. Org. Chem. 2002, 2002, 1903-1911.

(14) Suau, R.; Garcia-Segura, R.; Sanchez, C.; Pedraza, A. M. Photophthalimidation of unactivated double bonds. Synthesis of protected phenethylamines Tetrahedron Lett. 1999, 40, 2007-2010.

(15) Banerjee, R.; Bhatt, P. M.; Ravindra, N. V.; Desiraju, G. R. Saccharin salts of active pharmaceutical ingredients, their crystal structures, and increased water solubilities Cryst. Growth Des. 2005, 5, 2299-2309.

(16) Frisch, M. J.; Trucks, G. W.; Schlegel, H. B.; Scuseria, G. E.; Robb, M. A.; Cheeseman, J. R.; Scalmani, G.; Barone, V.; Mennucci, B.; Petersson, G. A.; Nakatsuji, H.; Caricato, M.; Li, X.; Hratchian, H. P.; Izmaylov, A. F.; Bloino, J. Z., G. ; Sonnenberg, J. L.; Hada, M.; Ehara, M.; Toyota, K.; Fukuda, R.; Hasegawa, J.; Ishida, M.; Nakajima, T.; Honda, Y.; Kitao, O.; Nakai, H.; Vreven, T.; Montgomery, J. A., Jr.; Peralta, J. E.; Ogliaro, F.; Bearpark, M.; Heyd, J. J.; Brothers, E.; Kudin, K. N.; Staroverov, V. N.; Kobayashi, R.; Normand, J.; Raghavachari, K.; Rendell, A.; Burant, J. C.; Iyengar, S. S.; Tomasi, J.; Cossi, M.; Rega, N.; Millam, N. J.; Klene, M.; Knox, J. E.; Cross, J. B.; Bakken, V.; Adamo, C.; Jaramillo, J.; Gomperts, R.; Stratmann, R. E.; Yazyev, O.; Austin, A. J.; Cammi, R.; Pomelli, C.; Ochterski, J. W.; Martin, R. L.; Morokuma, K.; Zakrzewski, V. G.; Voth, G. A.; Salvador, P.; Dannenberg, J. J.; Dapprich, S.; Daniels, A. D.; Farkas, Ö.; Foresman, J. B.; Ortiz, J. V.; Cioslowski, J.; Fox, D. J. Gaussian 09, Revision C.01. Gaussian, Inc.: Wallingford CT 2009,

(17) Peng, C.; Ayala, P. Y.; Schlegel, H. B. Using redundant internal coordinates to optimize equilibrium geometries and transition states J. Comput. Chem. 1996, 17, 4956. 
(18) Karlström, G.; Lindh, R.; Malmqvist, P.-Å.; Roos, B. O.; Ryde, U.; Veryazov, V.; Widmark, P.-O.; Cossi, M.; Schimmelpfennig, B.; Neogrady, P.; Seijo, L. MOLCAS: a program package for computational chemistry Comp. Mater. Sci. 2003, 28, 222-239.

(19) Bearpark, M. J.; Robb, M. A.; Schlegel, H. B. A direct method for the location of the lowest energy point on a potential surface crossing Chem. Phys. Lett. 1994, 233, 269-274. 